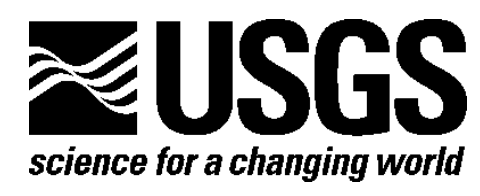

\title{
Users' Manual and Installation Guide for the EverVIEW Slice and Dice Tool (Version 1.0 Beta)
}

By Dustin Roszell, Craig Conzelmann, Sumani Chimmula, Anuradha Chandrasekaran, and Christina Hunnicut

Open-File Report 2009-1177

U.S. Department of the Interior

U.S. Geological Survey 


\section{U.S. Department of the Interior \\ KEN SALAZAR, Secretary}

\section{U.S. Geological Survey}

Suzette M. Kimball, Acting Director

U.S. Geological Survey, Reston, Virginia 2009

This and other USGS information products are available at http://store.usgs.gov/

U.S. Geological Survey

Box 25286, Denver Federal Center

Denver, CO 80225

To learn about the USGS and its information products visit http://www.usgs.gov/

1-888-ASK-USGS

Suggested citation:

Roszell, Dustin, Conzelmann, Craig, Chimmula, Sumani, Chandrasekaran, Anuradha, and Hunnicut, Christina, 2009, Users' manual and installation guide for the EverVIEW slice and dice tool (version 1.0 beta): U.S. Geological Survey Open-File Report 2009-1177, $40 \mathrm{p}$.

Any use of trade, product, or firm names is for descriptive purposes only and does not imply endorsement by the U.S. Government.

Although this report is in the public domain, permission must be secured from the individual copyright owners to reproduce any copyrighted material contained within this report. 


\section{Contents}

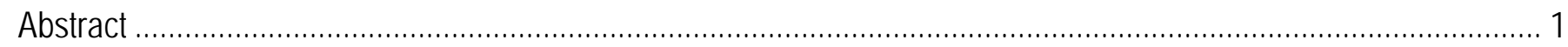

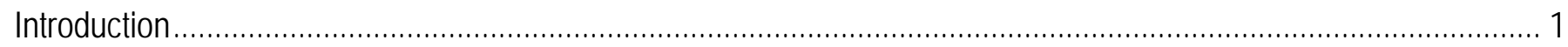

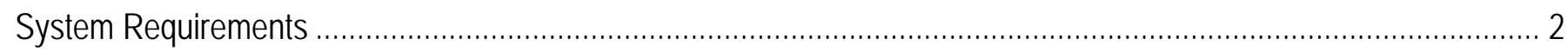

Data

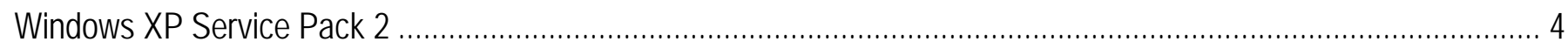

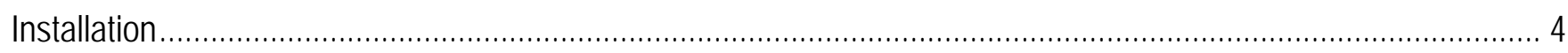

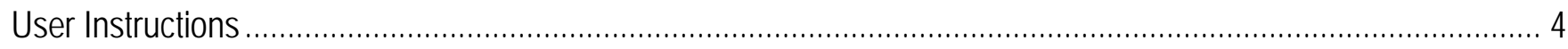

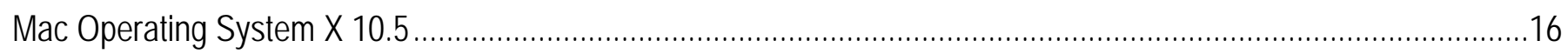

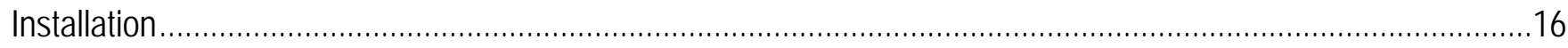

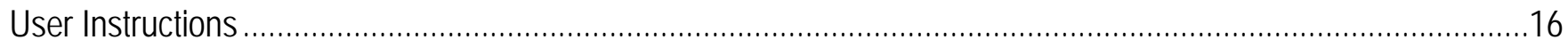

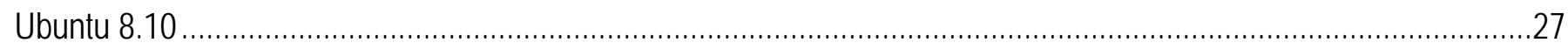

Installation

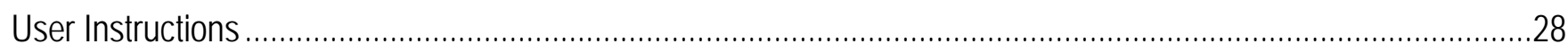

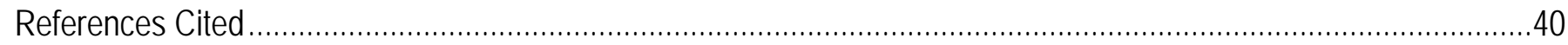

\section{Figures}

1. Windows XP Service Pack 2: Installation folder showing EverVIEW_NetCDFSDTool.exe ..................................... 4

2. Windows XP Service Pack 2: Automatic updates ………..................................................................... 5

3. Windows XP Service Pack 2: Opening a Network Common Data Form file …................................................... 6

4. Windows XP Service Pack 2: Previewing a Network Common Data Form file ...................................................... 7

5. Windows XP Service Pack 2: Table Viewer that is used to preview Network Common Data Form files ................... 8 


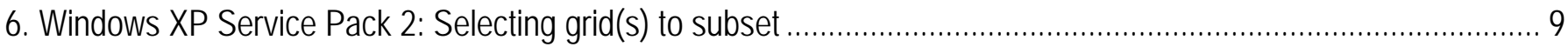

7. Windows XP Service Pack 2: Defining spatial and temporal bounds to subset files........................................... 10

8. Windows XP Service Pack 2: Saving the subsetted Network Common Data Form file ........................................ 11

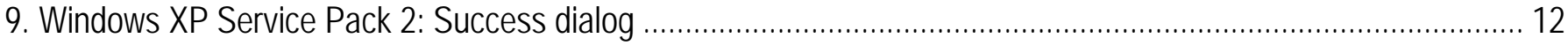

10. Windows XP Service Pack 2: Table Viewer showing the subsetted Network Common Data Form file ................. 13

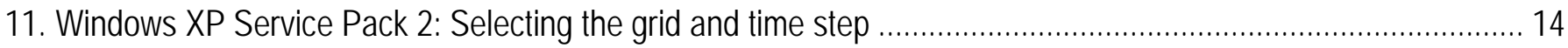

12. Windows XP Service Pack 2: Exporting a grid to a comma-separated value file............................................... 15

13. Mac Operating System X 10.5: Installation folder showing the EverVIEW_NetCDFSDTool executable ............... 16

14. Mac Operating System X 10.5: Opening a Network Common Data Form file ................................................. 17

15. Mac Operating System X 10.5: Previewing a Network Common Data Form file................................................... 18

16. Mac Operating System X 10.5: Table Viewer used to preview a Network Common Data Form file...................... 19

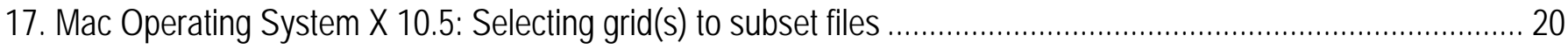

18. Mac Operating System X 10.5: Defining spatial and temporal bounds to subset files ........................................ 21

19. Mac Operating System X 10.5: Saving subsetted Network Common Data Form files ........................................... 22

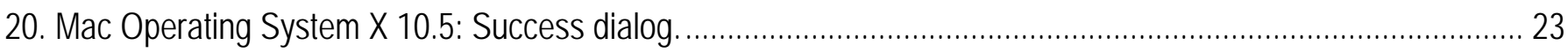

21. Mac Operating System X 10.5: Table Viewer showing the subsetted Network Common Data Form files............. 24

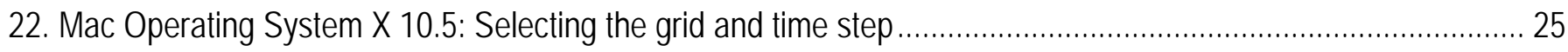

23. Mac Operating System X 10.5: Exporting a grid to a comma-separated value file .............................................. 26

24. Ubuntu 8.10: Installation folder showing the EverVIEW_NetCDFSDTool executable.......................................... 28

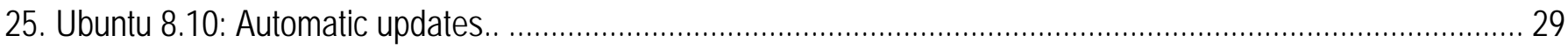

26. Ubuntu 8.10: Opening a Network Common Data Form file........................................................................... 30

27. Ubuntu 8.10: Previewing a Network Common Data Form file......................................................................... 31

28. Ubuntu 8.10: Table Viewer used to preview a Network Common Data Form file.............................................. 32

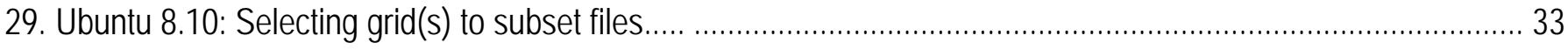




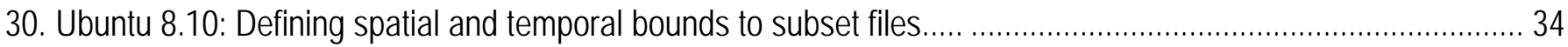

31. Ubuntu 8.10: Saving subsetted Network Common Data Form files .............................................................. 35

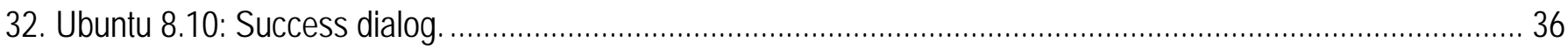

33. Ubuntu 8.10: Table Viewer showing subsetted Network Common Data Form files......................................... 37

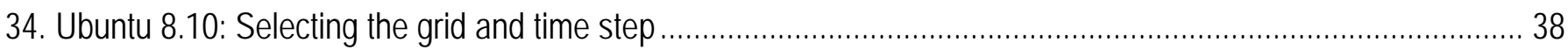

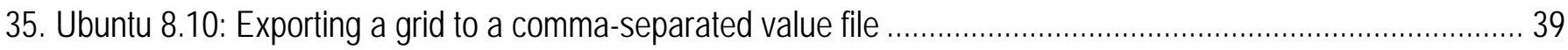




\title{
Users' Manual and Installation Guide for the EverVIEW
}

\section{Slice and Dice Tool (Version 1.0 Beta)}

By Dustin Roszell ${ }^{1}$, Craig Conzelmann ${ }^{2}$, Sumani Chimmula ${ }^{3}$, Anuradha Chandrasekaran ${ }^{4}$, and Christina Hunnicut ${ }^{1}$

\begin{abstract}
Network Common Data Form (NetCDF) is a self-describing, machine-independent file format for storing array-oriented scientific data. Over the past few years, there has been a growing movement within the community of natural resource managers in The Everglades, Fla., to use NetCDF as the standard data container for datasets based on multidimensional arrays. As a consequence, a need arose for additional tools to view and manipulate NetCDF datasets, specifically to create subsets of large NetCDF files. To address this need, we created the EverVIEW Slice and Dice Tool to allow users to create subsets of grid-based NetCDF files. The major functions of this tool are (1) to subset NetCDF files both spatially and temporally; (2) to view the NetCDF data in table form; and (3) to export filtered data to a comma-separated value file format.
\end{abstract}

\section{Introduction}

Network Common Data Form (NetCDF) is a self-describing, machine-independent file format for storing array-oriented scientific data. It was created by the Unidata Program Center at the University

\footnotetext{
${ }^{1}$ IAP Worldwide Services, Inc.

${ }^{2}$ U.S. Geological Survey

${ }^{3}$ University of Louisiana at Lafayette

${ }^{4}$ ASci Corporation
} 
Corporation for Atmospheric Research (UCAR), in conjunction with the National Aeronautics and Space Administration (NASA) and other organizations, to provide a common interface between applications and real-time meteorological and other scientific data. (Unidata Program Center, 2009).

Over the past few years, there has been a growing movement within the community of natural resource managers in The Everglades, Fla., to use NetCDF as the standard data container for datasets based on multidimensional arrays. As a consequence, a need arose for additional tools to view and manipulate NetCDF datasets, specifically to create subsets of large NetCDF files. To address this need, we created the EverVIEW Slice and Dice Tool to allow users to create subsets of grid-based NetCDF files. The major functions of this tool are (1) to subset NetCDF files both spatially and temporally; (2) to view the NetCDF data in table form; and (3) to export filtered data to a comma-separated value (CSV) file format.

\section{System Requirements}

The EverVIEW Slice and Dice Tool requires that Java Runtime Environment (JRE) 5 (Sun Microsystems, Inc., Santa Clara, Calif.) or higher be installed. The JRE 5 software can be downloaded from http://java.sun.com/javase/downloads/index.jsp. The slice and dice tool has been tested on the following operating systems (OS): Windows XP Service Pack 2 (Microsoft Corporation, Redmond, Wash.), Mac OS X 10.5 (Apple, Cupertino, Calif.), and Ubuntu 8.10 (Canonical Ltd., Douglas, Isle of Man)

\section{Data}

This tool has been tested extensively with NetCDF data containing water surfaces from the Everglades Depth Estimation Network (EDEN). Limited testing has been done with multigrid datasets and other datasets that are compliant with the climate and forecast (CF) metadata standards (version1.0) 
for NetCDF files, but there are no guarantees as to what does and does not work. The tool should subset most 3-dimensional grids based on time and two coordinates. The tool will not subset NetCDF files containing variables that define the grid-cell boundaries of coordinate variables (http://cfpcmdi.llnl.gov/documents/cf-conventions/1.0/cf-conventions.html\#cell-boundaries), two-dimensional coordinate variables (http://cf-pcmdi.llnl.gov/documents/cf-conventions/1.0/cfconventions.html\#id2888361), or any other nongrid variables dependent upon the subsetted dimensions. 


\section{Windows XP Service Pack 2}

\section{Installation}

The software is available for download at http://jem.cr.usgs.gov/everview.aspx. Extract the zip file into a folder on your local machine and run the executable file. This software requires write permission to the installation directory in order to function properly.

\section{User Instructions}

1. Run the application. To do this, navigate to the folder where the tool is installed and double click on EverVIEW_NetCDFSDTool.exe. The application can only be run from this directory, because it depends on other files and folders in the installation directory.

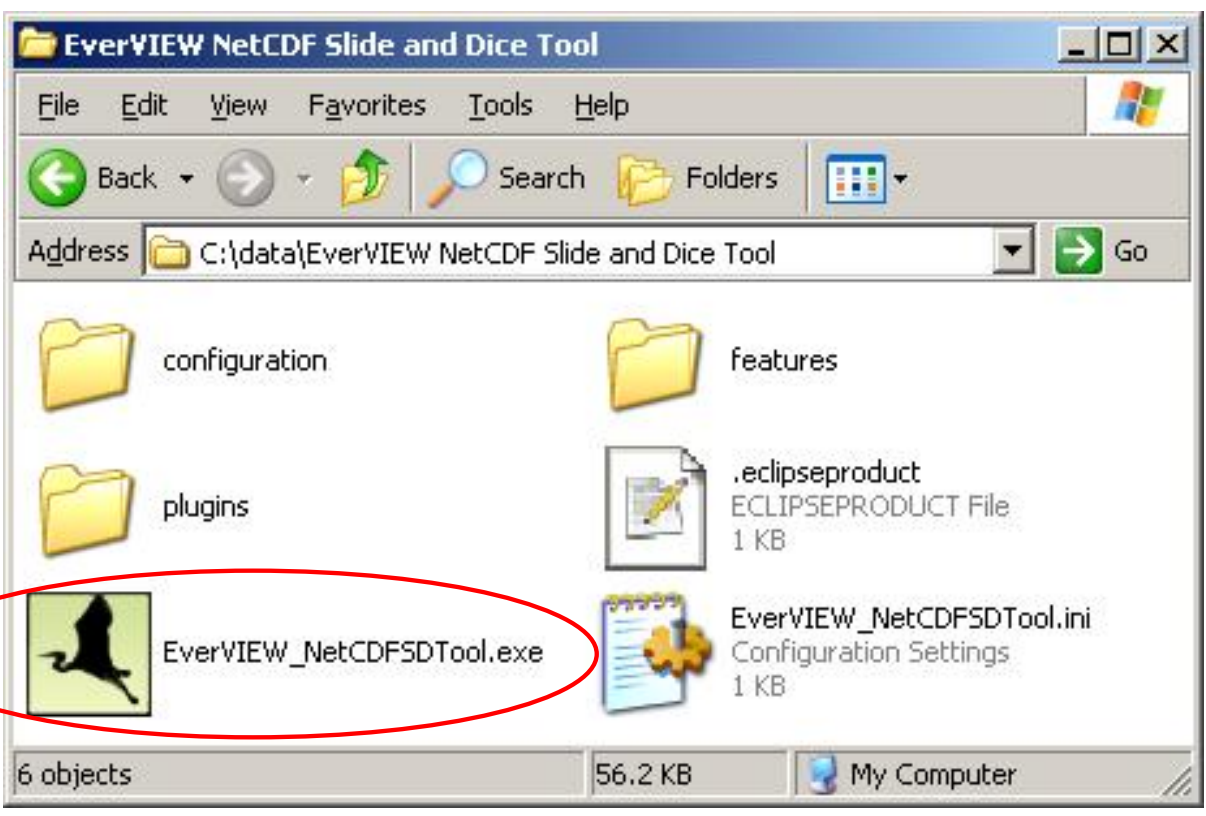

Figure 1. Windows XP Service Pack 2: Installation folder showing EverVIEW_NetCDFSDTool.exe. 
2. The EverVIEW NetCDF Slice and Dice Tool will open and check to see if any updates are available. If updates are available, you will be prompted to install them.

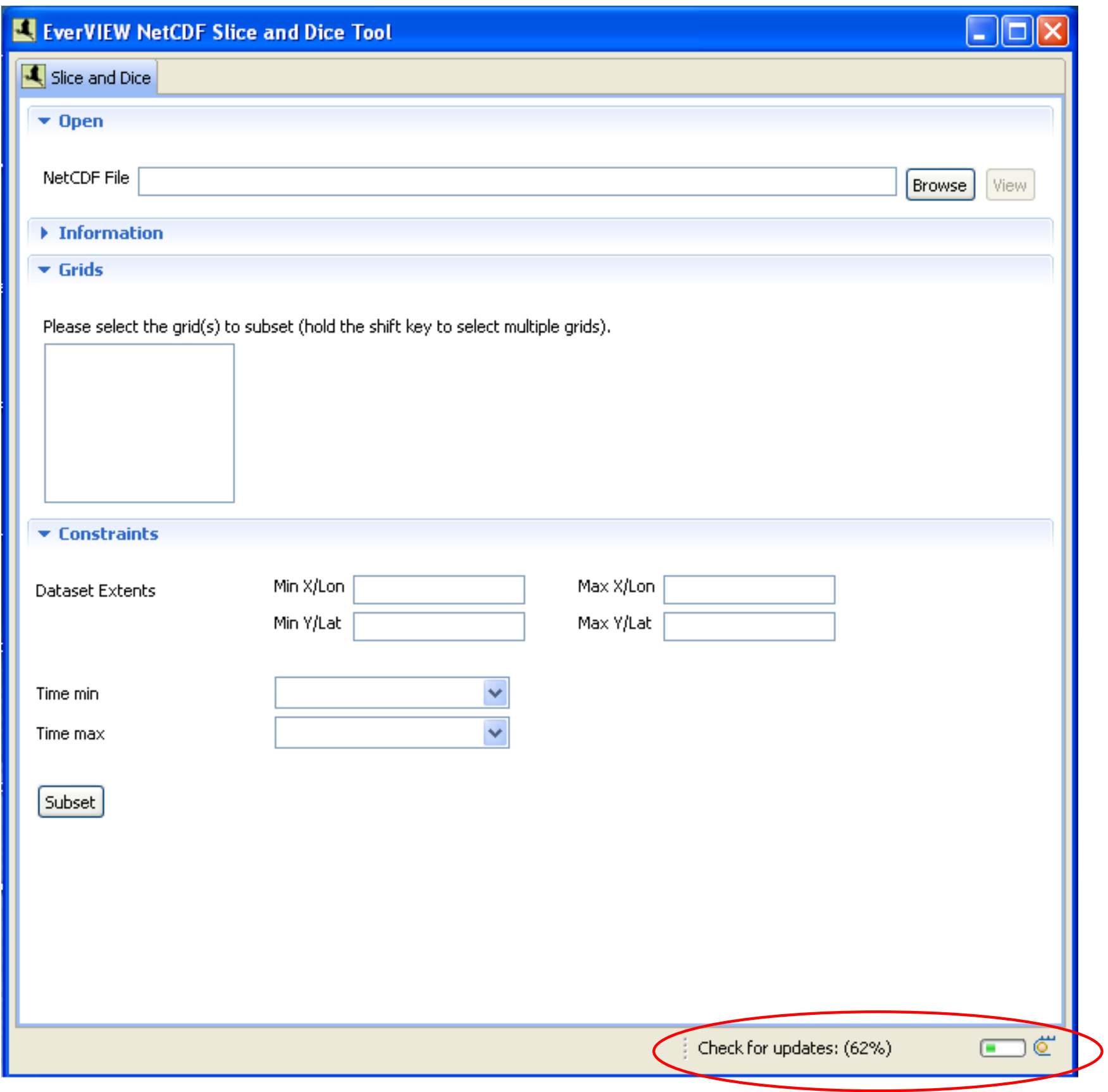

Figure 2. Windows XP Service Pack 2: Automatic updates. 
3. Click the "Browse" button and select the NetCDF file to subset.

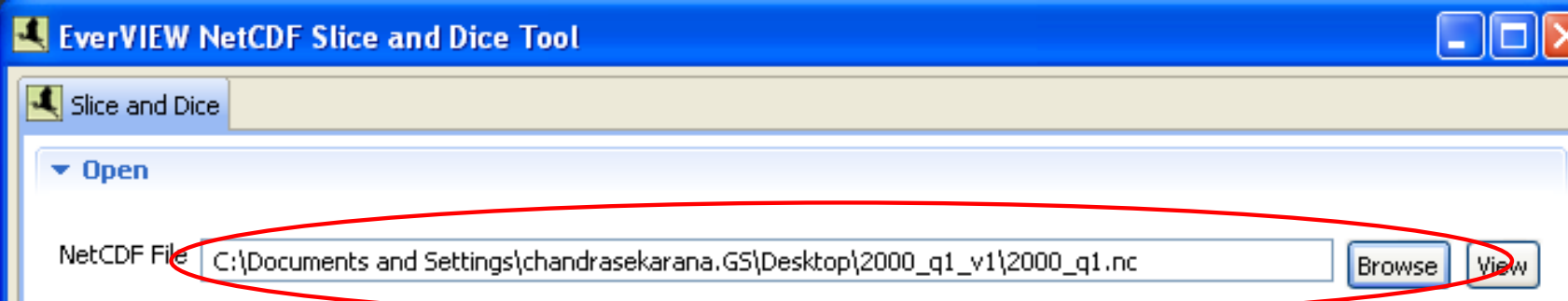

- Information

- Grids

Please select the grid(s) to subset (hold the shift key to select multiple grids).

stage

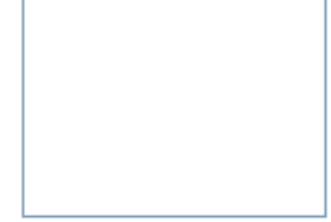

- Constraints

Dataset Extents

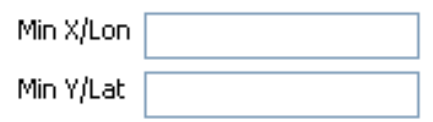

MaxXíLon

Max YilLat

Time min

Time max

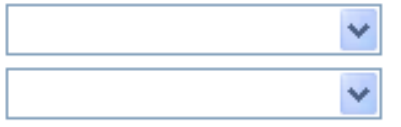

Subset

Figure 3. Windows XP Service Pack 2: Opening a Network Common Data Form (NetCDF) file in the EverVIEW NetCDF Slice and Dice Tool. 
4. If you would like to preview the original NetCDF file, click the "View" button.

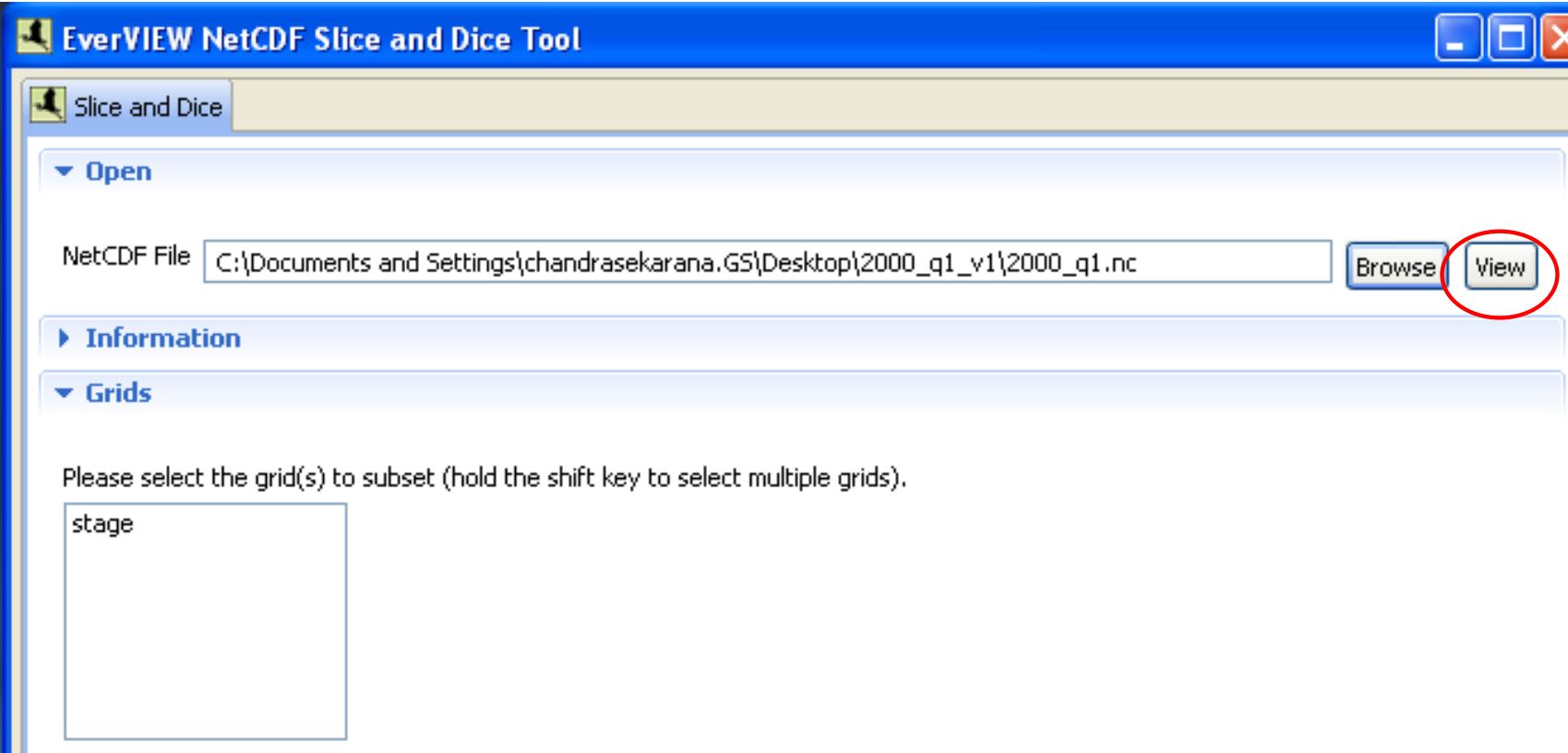

- Constraints

Dataset Extents
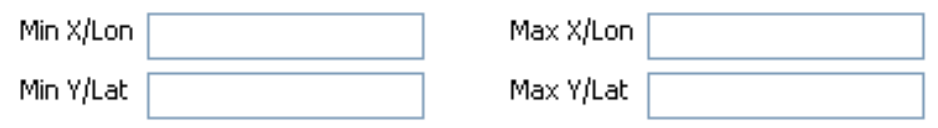

Time min

Time max

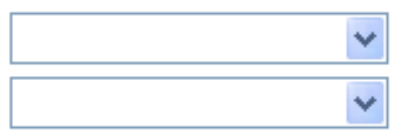

Subset

Figure 4. Windows XP Service Pack 2: Previewing a Network Common Data Form (NetCDF) file in the EverVIEW NetCDF Slice and Dice Tool. 
5. After clicking the "View" button, the NetCDF Table Viewer will be shown with the NetCDF file you selected.

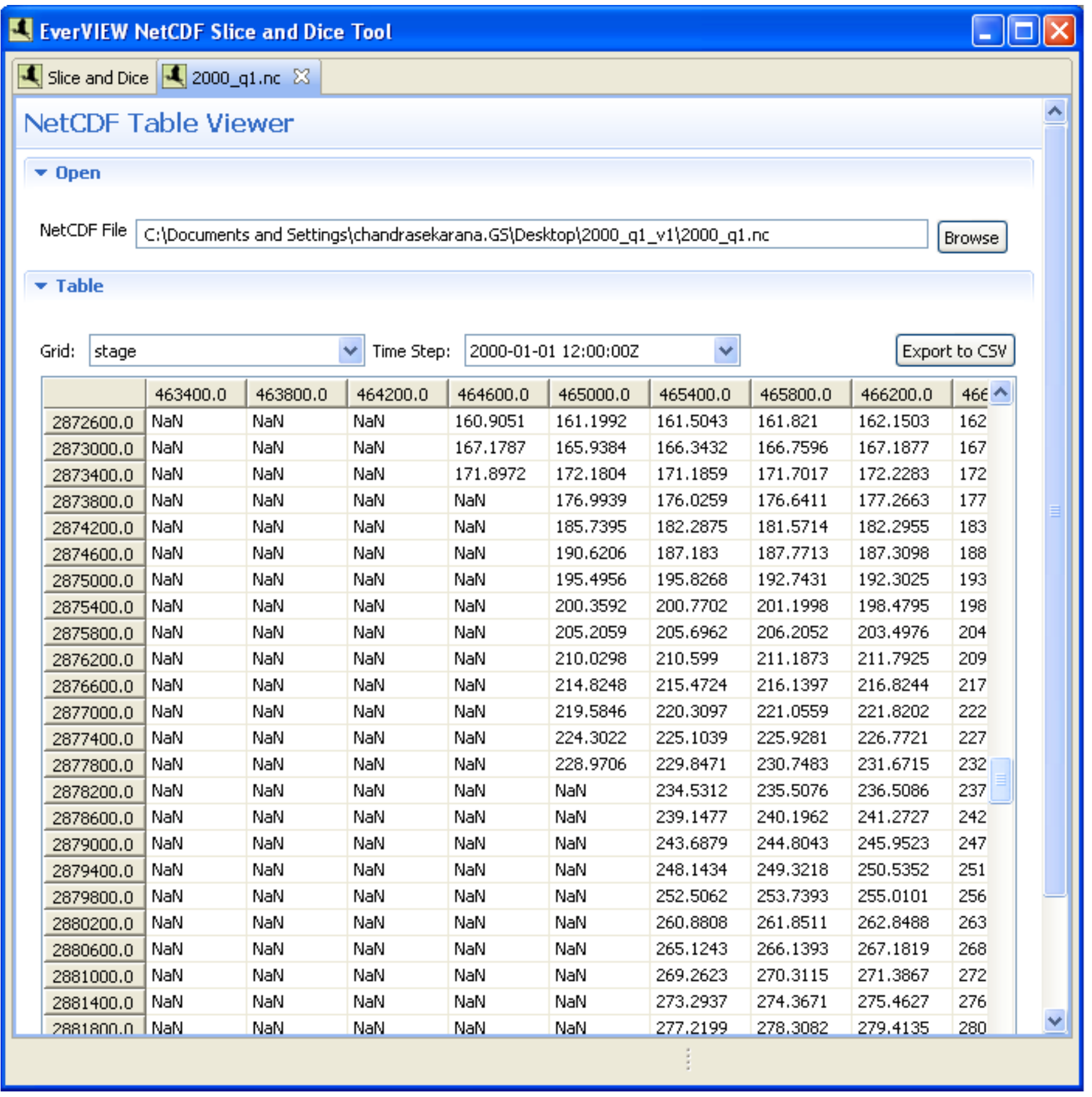

Figure 5. Windows XP Service Pack 2: Table Viewer that is used to preview Network Common Data Form (NetCDF) files in the EverVIEW NetCDF Slice and Dice Tool. 
6. After you have finished previewing the file, click the "Slice and Dice" tab at the top. Select the grid variable(s) that you want to subset. You can select more than one grid variable by holding the shift or control key while clicking them.

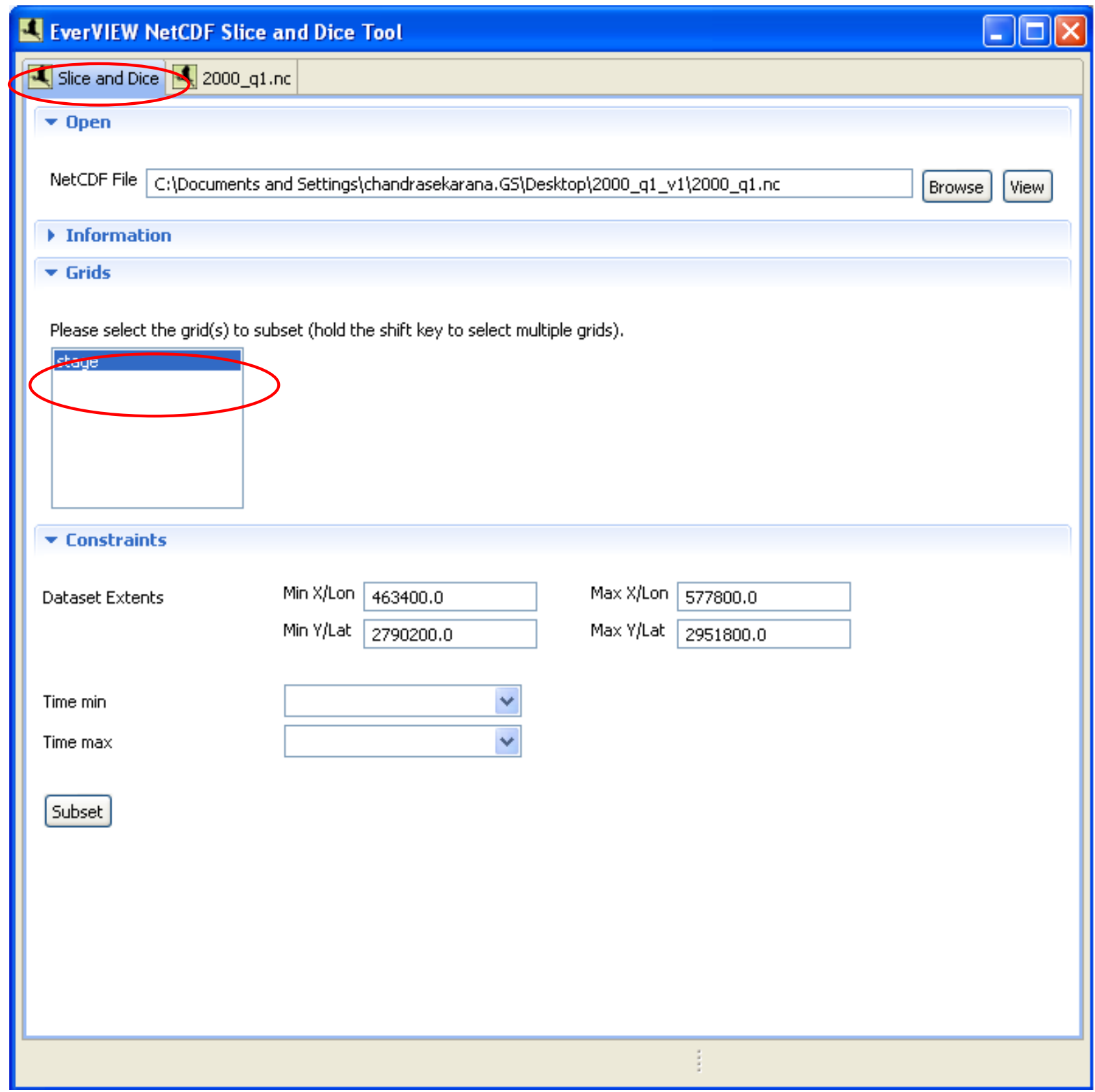

Figure 6. Windows XP Service Pack 2: Selecting grid(s) within the EverVIEW Slice and Dice Tool in order to subset Network Common Data Form (NetCDF) files. 
7. After selecting the grid(s), the minimum and maximum $x / y$ or lattitude/longitude values will be populated in the "Dataset Extents" section.

8. Select the temporal bounds by specifying the start date and the end date from the drop down lists.

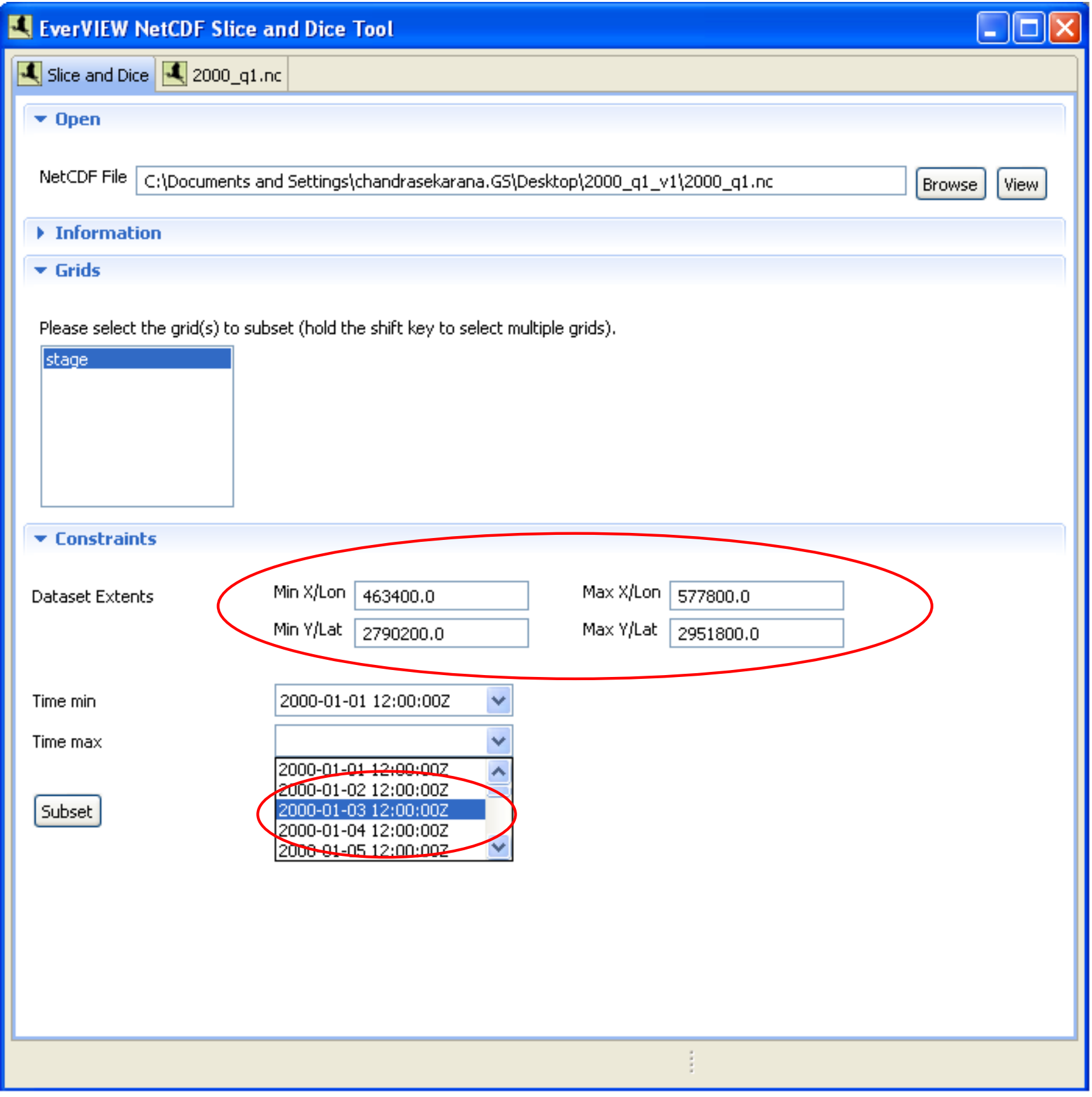

Figure 7. Windows XP Service Pack 2: Defining spatial and temporal bounds in the EverVIEW Slice and Dice Tool in order to subset files. 
9. Click on the "Subset" button to subset the data according to the specified constraints.

10. After clicking "Subset," a prompt will appear asking where to save the subsetted NetCDF file. Type in the name of a new NetCDF file, or select an existing NetCDF file, and click the "Save" button. The subsetted file will automatically be saved with a ".nc" extension.

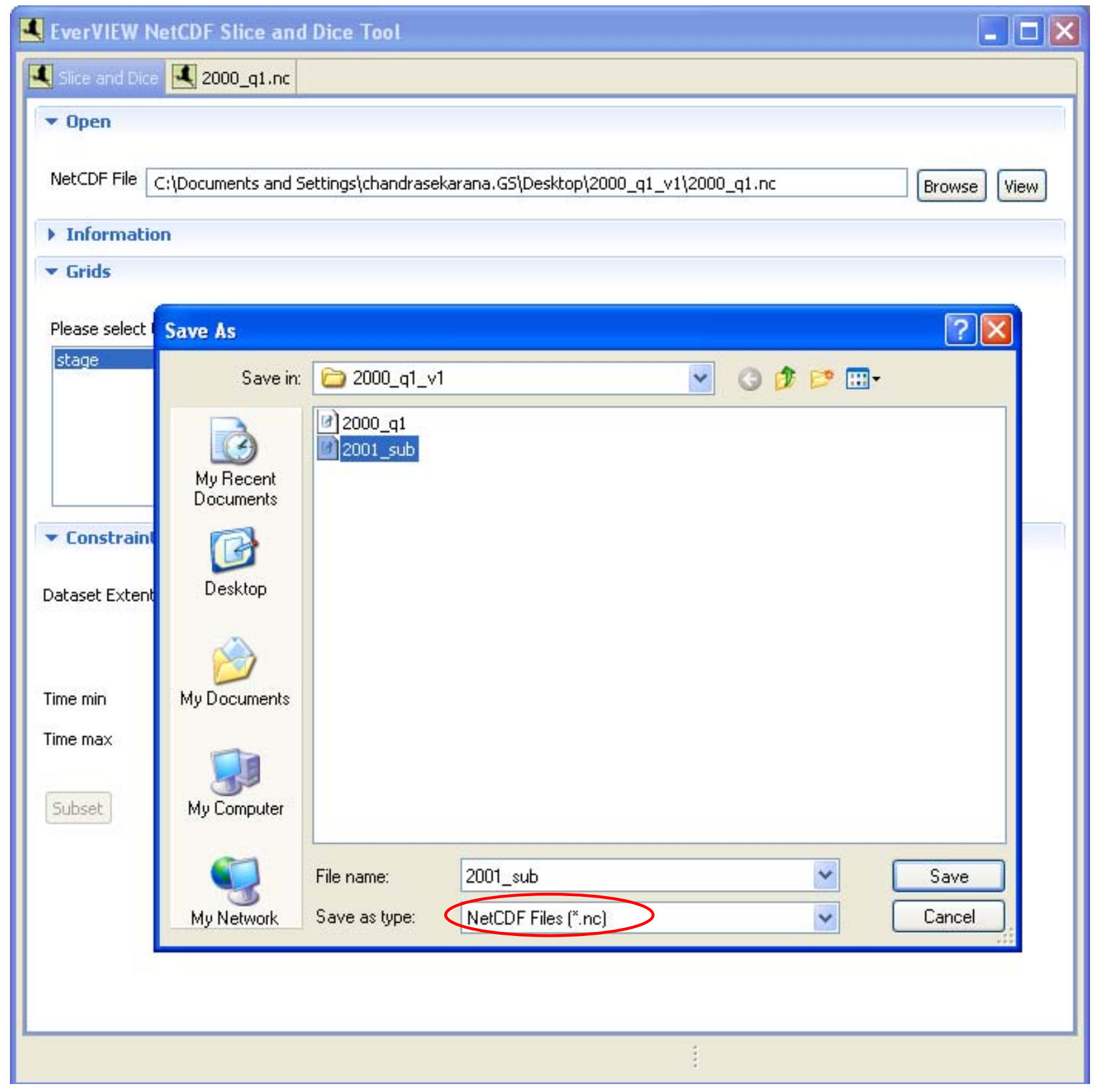

Figure 8. Windows XP Service Pack 2: Saving the subsetted Network Common Data Form (NetCDF) file in the EverVIEW NetCDF Slice and Dice Tool. 
11. Once the new NetCDF file has been created, a dialog box will appear letting you know that it was successful.

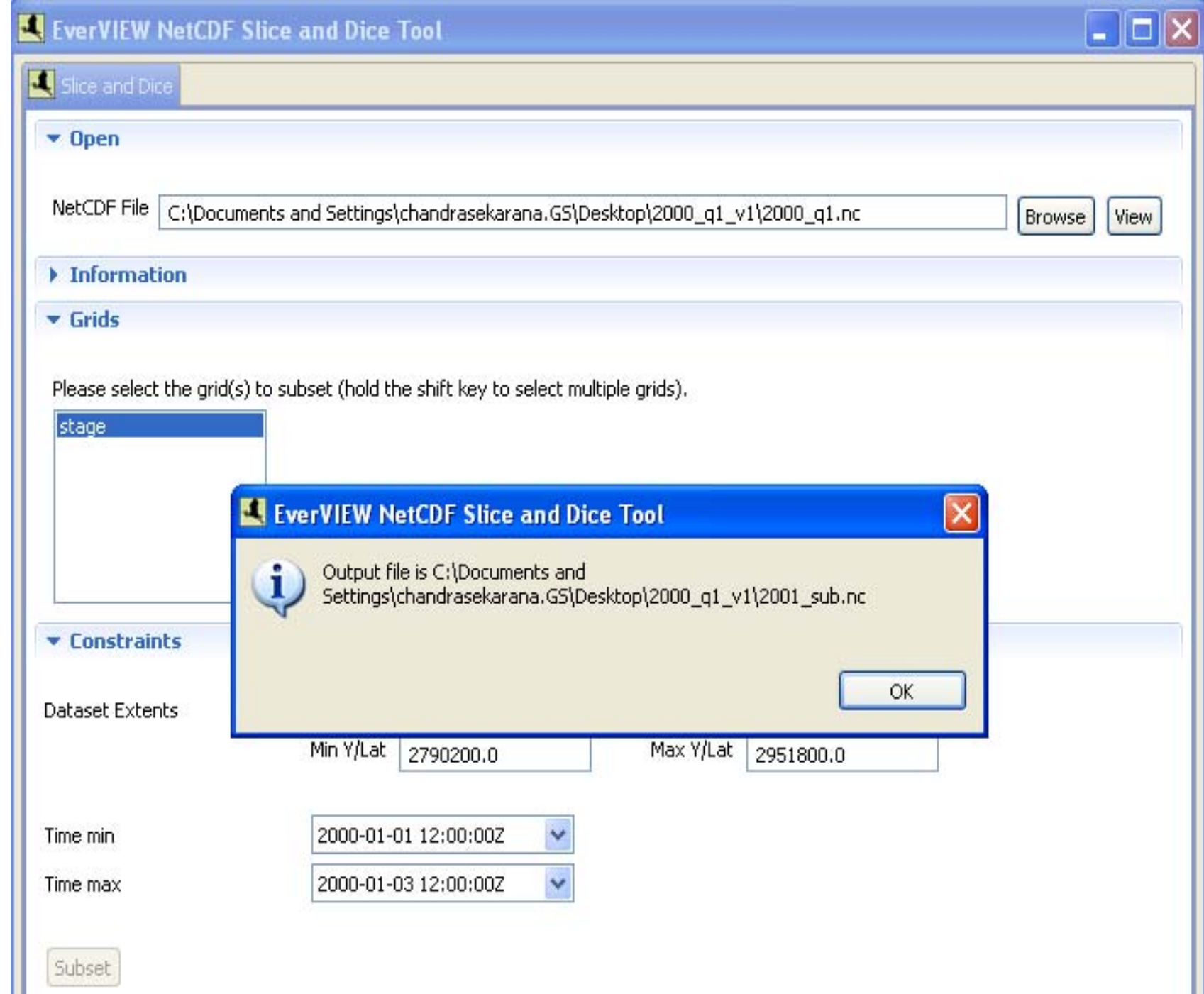

Figure 9. Windows XP Service Pack 2: Success dialog. 
12. The newly created NetCDF file will automatically open in the NetCDF Table Viewer.

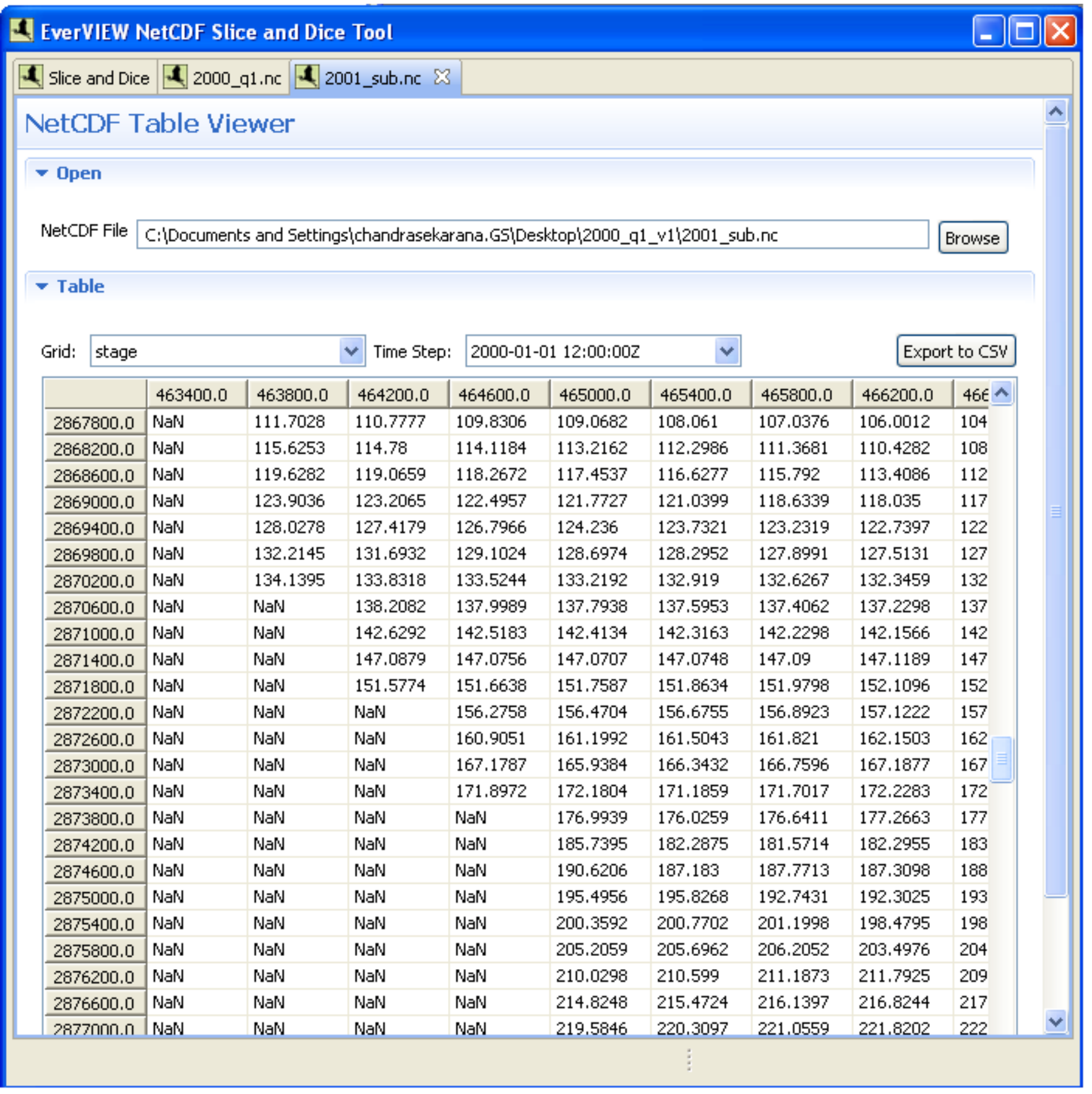

Figure 10. Windows XP Service Pack 2: Table Viewer in the EverVIEW Slice and Dice Tool showing the subsetted Network Common Data Form (NetCDF) files. 
13. From here, you can select the grid variable and time step for which you want to view data.

\begin{tabular}{|c|c|c|c|c|c|c|c|c|c|c|c|}
\hline \multicolumn{9}{|c|}{ A EverVIEW NetCDF Slice and Dice Tool } & \multirow{2}{*}{\multicolumn{2}{|c|}{$\square$}} & \multirow[t]{2}{*}{$x$} \\
\hline $\mathbf{4}$ slice and Dic & $\mathbf{4} 2000$ & q1.nc $x_{2}$ & 1_sub.nc & & & & & & & & \\
\hline \multicolumn{11}{|c|}{ NetCDF Table Viewer } & $\wedge$ \\
\hline \multicolumn{12}{|l|}{ - Open } \\
\hline NetCDF File & \multicolumn{8}{|c|}{ 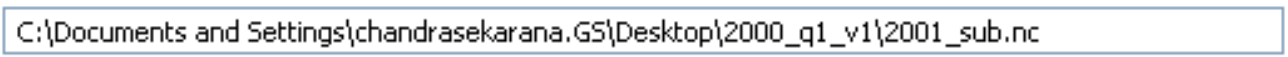 } & Browse & & \\
\hline \multicolumn{12}{|l|}{ Table } \\
\hline \multirow[t]{2}{*}{ Grid: stage } & & & Time Ste & $2000-01$ & $12: 00: 002$ & & \multicolumn{4}{|c|}{ Export to CSV } & \\
\hline & 463400.0 & 463800.0 & 464200.0 & 464600.0 & 465000.0 & 465400.0 & 465800.0 & 466200.0 & $46 \epsilon \wedge$ & & \\
\hline 2867800.0 & $\mathrm{NaN}$ & 111.7028 & 110.7777 & 109.8306 & 109.0682 & 108.061 & 107.0376 & 106.0012 & 104 & & \\
\hline 2868200.0 & NaN & 115.6253 & 114.78 & 114.1184 & 113.2162 & 112.2986 & 111.3681 & 110.4282 & 108 & & \\
\hline 2868600.0 & $\mathrm{NaN}$ & 119.6282 & 119.0659 & 118.2672 & 117.4537 & 116.6277 & 115.792 & 113.4086 & 112 & & \\
\hline 2869000.0 & $\mathrm{NaN}$ & 123.9036 & 123.2065 & 122.4957 & 121.7727 & 121.0399 & 118.6339 & 118.035 & 117 & & \\
\hline 2869400.0 & $\mathrm{NaN}$ & 128.0278 & 127.4179 & 126.7966 & 124.236 & 123.7321 & 123.2319 & 122.7397 & 122 & & \\
\hline 2869800.0 & $\mathrm{NaN}$ & 132.2145 & 131.6932 & 129.1024 & 128.6974 & 128.2952 & 127.8991 & 127.5131 & 127 & & \\
\hline 2870200.0 & $\mathrm{NaN}$ & 134.1395 & 133.8318 & 133.5244 & 133.2192 & 132.919 & 132.6267 & 132.3459 & 132 & & \\
\hline 2870600.0 & $\mathrm{NaN}$ & $\mathrm{NaN}$ & 138.2082 & 137.9989 & 137.7938 & 137.5953 & 137.4062 & 137.2298 & 137 & & \\
\hline 2871000.0 & $\mathrm{NaN}$ & $\mathrm{NaN}$ & 142.6292 & 142.5183 & 142.4134 & 142.3163 & 142.2298 & 142.1566 & 142 & & \\
\hline 2871400.0 & $\mathrm{NaN}$ & $\mathrm{NaN}$ & 147.0879 & 147.0756 & 147.0707 & 147.0748 & 147.09 & 147.1189 & 147 & & \\
\hline 2871800.0 & $\mathrm{NaN}$ & $\mathrm{NaN}$ & 151.5774 & 151.6638 & 151.7587 & 151.8634 & 151.9798 & 152.1096 & 152 & & \\
\hline 2872200.0 & $\mathrm{NaN}$ & NaN & $\mathrm{NaN}$ & 156.2758 & 156.4704 & 156.6755 & 156.8923 & 157.1222 & 157 & & \\
\hline 2872600.0 & $\mathrm{NaN}$ & $\mathrm{NaN}$ & $\mathrm{NaN}$ & 160.9051 & 161.1992 & 161.5043 & 161.821 & 162.1503 & 162 & & \\
\hline 2873000.0 & $\mathrm{NaN}$ & $\mathrm{NaN}$ & $\mathrm{NaN}$ & 167.1787 & 165.9384 & 166.3432 & 166.7596 & 167.1877 & 167 & & \\
\hline 2873400.0 & $\mathrm{NaN}$ & $\mathrm{NaN}$ & $\mathrm{NaN}$ & 171.8972 & 172.1804 & 171.1859 & 171.7017 & 172.2283 & 172 & & \\
\hline 2873800.0 & $\mathrm{NaN}$ & $\mathrm{NaN}$ & $\mathrm{NaN}$ & $\mathrm{NaN}$ & 176.9939 & 176.0259 & 176.6411 & 177.2663 & 177 & & \\
\hline 2874200.0 & $\mathrm{NaN}$ & $\mathrm{NaN}$ & $\mathrm{NaN}$ & $\mathrm{NaN}$ & 185.7395 & 182.2875 & 181.5714 & 182.2955 & 183 & & \\
\hline 2874600.0 & $\mathrm{NaN}$ & $\mathrm{NaN}$ & $\mathrm{NaN}$ & $\mathrm{NaN}$ & 190.6206 & 187.183 & 187.7713 & 187.3098 & 188 & & \\
\hline 2875000.0 & NaN & $\mathrm{NaN}$ & $\mathrm{NaN}$ & $\mathrm{NaN}$ & 195.4956 & 195.8268 & 192.7431 & 192.3025 & 193 & & \\
\hline 2875400.0 & $\mathrm{NaN}$ & $\mathrm{NaN}$ & $\mathrm{NaN}$ & $\mathrm{NaN}$ & 200.3592 & 200.7702 & 201.1998 & 198.4795 & 198 & & \\
\hline 2875800.0 & $\mathrm{NaN}$ & NaN & $\mathrm{NaN}$ & $\mathrm{NaN}$ & 205.2059 & 205.6962 & 206.2052 & 203.4976 & 204 & & \\
\hline 2876200.0 & $\mathrm{NaN}$ & $\mathrm{NaN}$ & $\mathrm{NaN}$ & $\mathrm{NaN}$ & 210.0298 & 210.599 & 211.1873 & 211.7925 & 209 & & \\
\hline 2876600.0 & $\mathrm{NaN}$ & $\mathrm{NaN}$ & $\mathrm{NaN}$ & $\mathrm{NaN}$ & 214.8248 & 215.4724 & 216.1397 & 216.8244 & 217 & & \\
\hline $28770 n$ ก & $\mathrm{NaN}$ & $\mathrm{NaN}$ & $\mathrm{NaN}$ & $\mathrm{NaN}$ & 219.5846 & 220.3097 & 221.0559 & 221.8202 & 222 & & $v$ \\
\hline
\end{tabular}

Figure 11. Windows XP Service Pack 2: Selecting the grid and time step in the EverVIEW Slice and Dice Tool Table Viewer. 
14. From this view, you can also export the data for the current Grid and Time Step to CSV format by clicking the "Export to CSV” button.

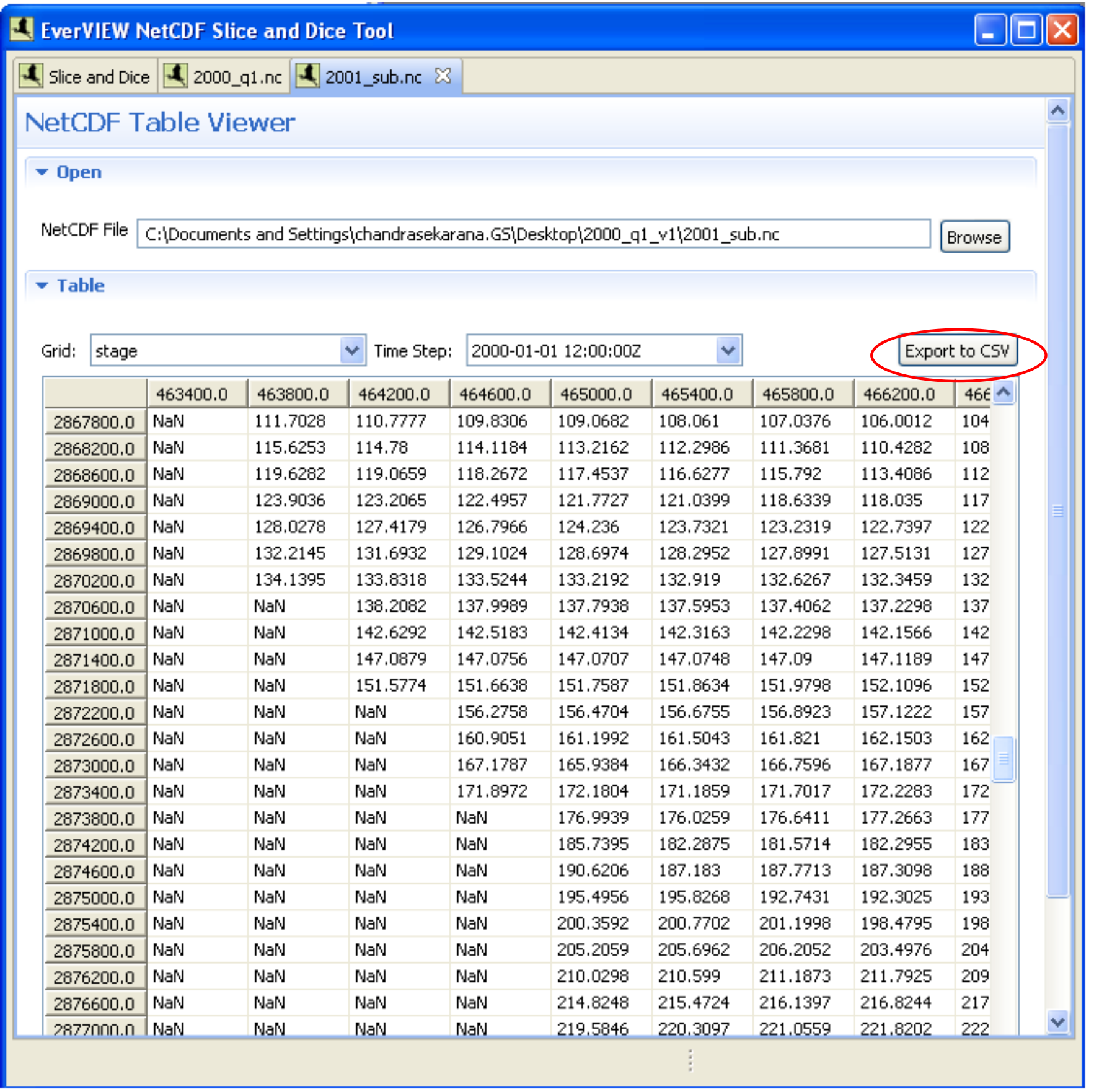

Figure 12. Windows XP Service Pack 2: Exporting a grid to a comma-separated value (CSV) file in the EverVIEW NetCDF Slice and Dice Tool. 


\section{Mac Operating System X 10.5}

\section{Installation}

Download the image file (.dmg) and double click on it to mount the software. Some users may prefer to drag the “EverVIEW NetCDF Slice and Dice Tool” into the applications directory. This software requires write permission to the installation directory in order to function properly.

\section{User Instructions}

1. Run the application. To do this, navigate to the folder where the tool is installed and double click on EverVIEW_NetCDFSDTool application. The application can only be run from this directory, because it depends on other files and folders in the installation directory.

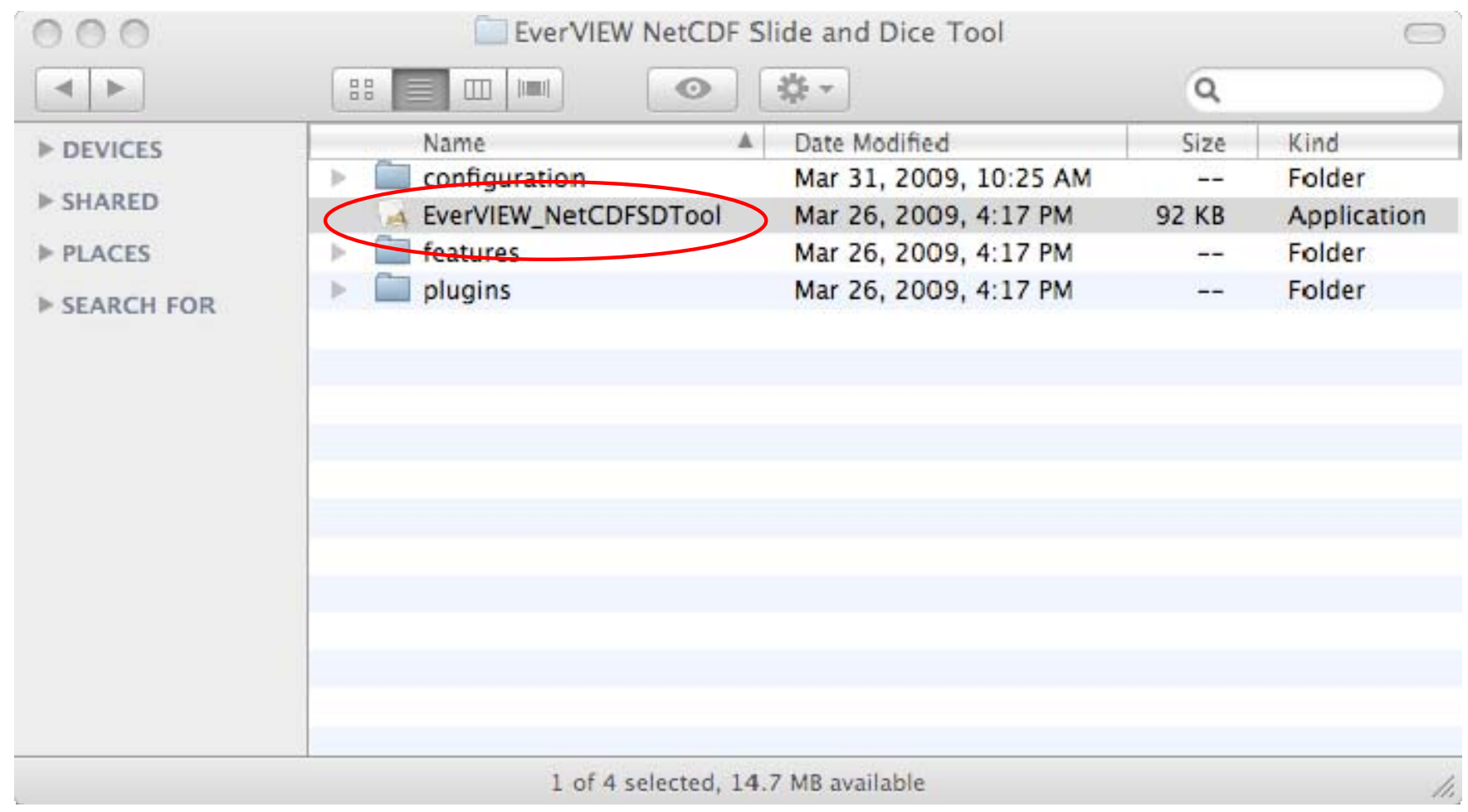

Figure 13. Mac Operating System X 10.5: Installation folder showing the EverVIEW_NetCDFSDTool executable. 
2. The EverVIEW NetCDF Slice and Dice Tool will open and check to see if any updates are available. If updates are available, they will be installed automatically.

3. Click the "Browse" button and select the NetCDF file to subset.

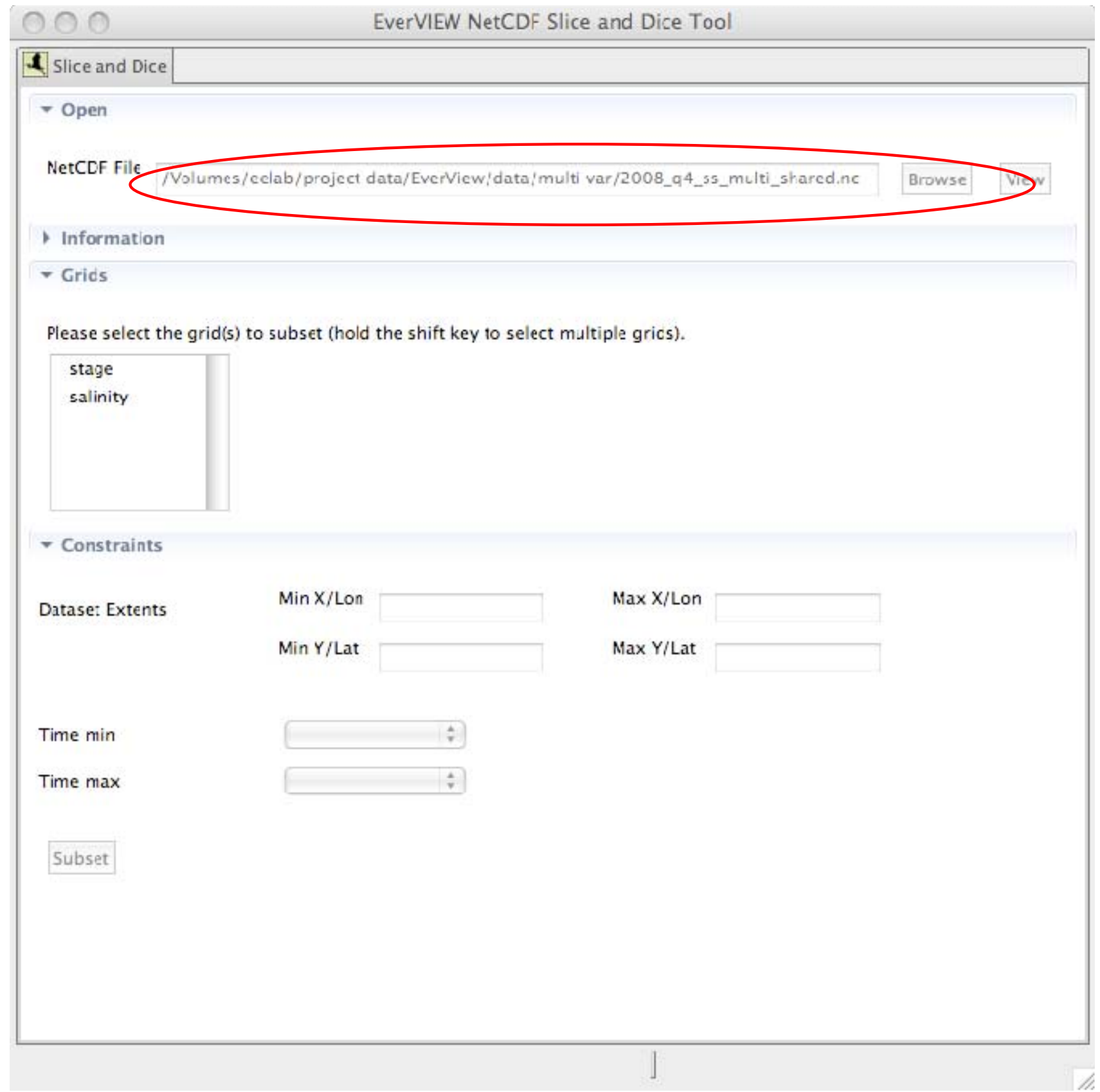

Figure 14. Mac Operating System X 10.5: Opening a Network Common Data Form (NetCDF) file in the EverVIEW NetCDF Slice and Dice Tool. 
4. If you would like to preview the original NetCDF file, click the "View" button.

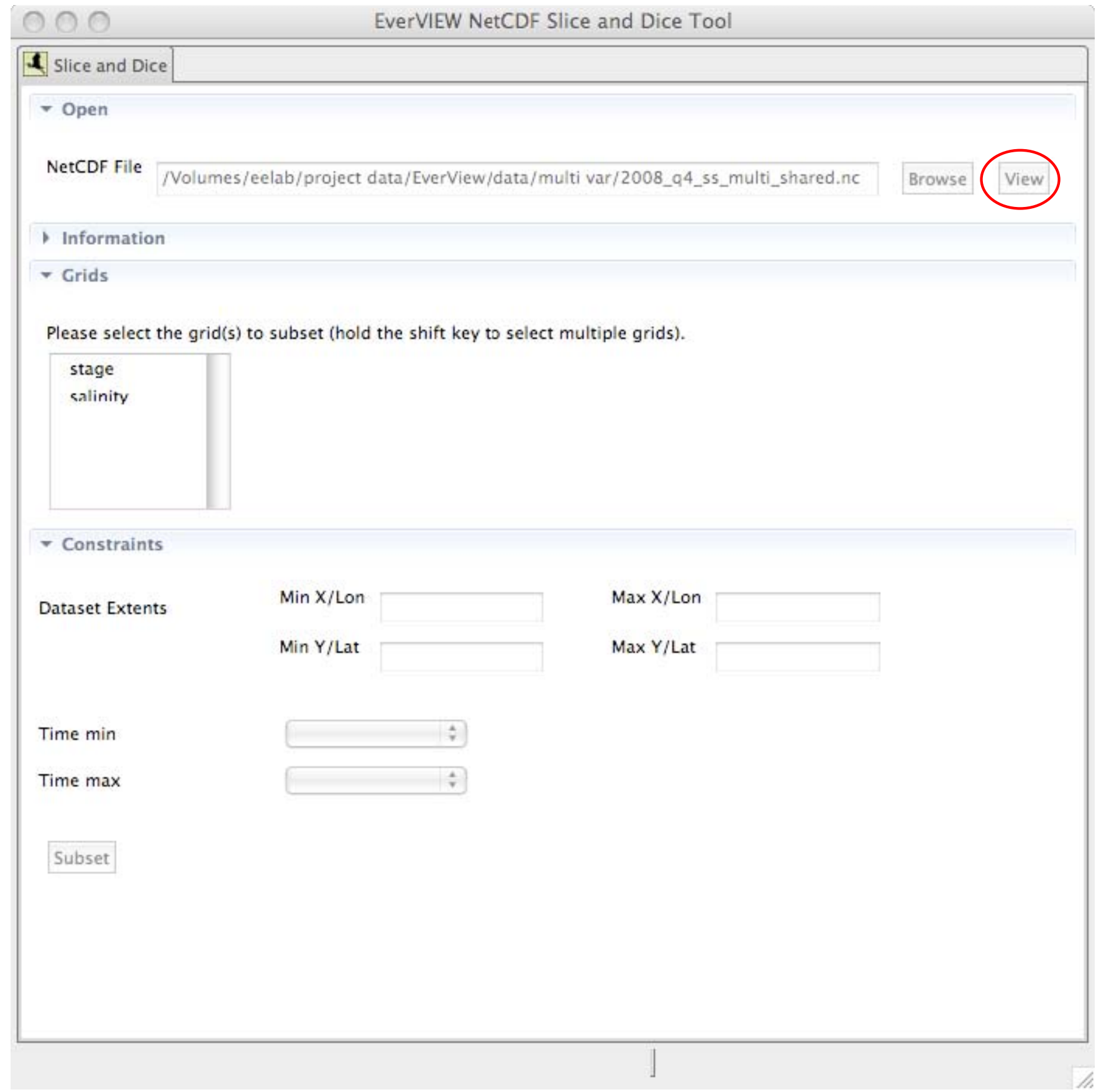

Figure 15. Mac Operating System X 10.5: Previewing a Network Common Data Form (NetCDF) file in the EverVIEW NetCDF Slice and Dice tool. 
5. After clicking the "View" button, the NetCDF Table Viewer will be shown with the NetCDF file you selected.

\section{EverVIEW NetCDF Slice and Dice Tool}

Slice and Dice 1 2008_94_5s_multi_shared.nc 23

\section{NetCDF Table Viewer}

- Open

NetCDF File

Nolumes/eelab/project data/EverView/data/multi var/2008_q4_ss_multi_shared.nc

Browse

- Table

Grid: stage

Time Step:

$2008-10-0112: 0 \ldots \ldots$

Export to CSV

\begin{tabular}{|c|c|c|c|c|c|c|c|c|c|}
\hline & 553400.0 & 553800.0 & 554200.0 & 554600.0 & 555000.0 & 555400.0 & 555800.0 & 556200.0 & 55 \\
\hline 2910200.0 & 362.8875 & 362.7675 & 362.9888 & 371.7638 & 363.4534 & 370.9098 & 370.5418 & 370.2265 & 36 ? \\
\hline 2910600.0 & 362.5999 & 362.8625 & 363.1462 & 363.4497 & 363.7578 & 363.98 & 364.3496 & 364.7349 & $36:$ \\
\hline 2911000.0 & 362.4211 & 362.8372 & 363.3105 & 363.4674 & 363.8982 & 364.3523 & 364.7552 & 365.1681 & $36:$ \\
\hline 2911400.0 & 362.0707 & 362.5746 & 363.1313 & 363.6758 & 364.1805 & 364.6978 & 365.1468 & 365.4887 & $36:$ \\
\hline 2911800.0 & 361.7184 & 362.4759 & 363.196 & 363.8357 & 364.4357 & 364.9432 & 365.4429 & 365.9076 & $36 t$ \\
\hline$\angle 91 \angle 200.0$ & 361.3881 & 362.3556 & 363.1988 & 363.9464 & 364.6899 & 365.2838 & 365.8291 & 366.3356 & $36 \mathrm{t}$ \\
\hline 2912600.0 & 361.2 & 362.2707 & 363.2328 & 364.1006 & 364.9387 & 365.5982 & 366.2065 & 366.7164 & $36:$ \\
\hline 2913000.0 & 360.9099 & 362.141 & 363.244 & 364.2323 & 365.222 & 365.9455 & 366.5786 & 367.148 & $36:$ \\
\hline 2913400.0 & 357.3155 & 358.1967 & 359.0389 & 359.9296 & 365.502 & 366.2787 & 366.9607 & 367.5633 & 362 \\
\hline 2913800.0 & 358.656 & 359.246 & 360.2679 & 360.9362 & 361.7177 & 362.3543 & 362.9854 & 363.6771 & 36 \\
\hline 2914200.0 & 363.1357 & 360.7092 & 361.3052 & 358.9199 & 360.557 & 363.3854 & 363.9658 & 364.4895 & $36 !$ \\
\hline 2914600.0 & 363.909 & 364.9927 & 365.8968 & 363.1971 & 363.6851 & 367.8208 & 368.2019 & 364.7222 & $36 t$ \\
\hline 2915000.0 & 364.726 & 365.8477 & 366.7695 & 364.1061 & 364.6322 & 365.055 & 368.9695 & 370.0874 & 370 \\
\hline 2915400.0 & 365.6471 & 366.7923 & 367.7142 & 365.1706 & 365.5829 & 366.5797 & 366.9489 & 370.779 & 370 \\
\hline 2915800.0 & 366.6577 & 367.8176 & 368.7468 & 366.2927 & 367.2117 & 367.5913 & 367.9641 & 368.2708 & 37: \\
\hline 2916200.0 & 367.6464 & 368.7681 & 370.1626 & 367.7312 & 368.3586 & 368.6768 & 368.9363 & 369.1691 & $37 \%$ \\
\hline 2916600.0 & 368.7979 & 370.3381 & 368.8083 & 369.0618 & 369.2509 & 369.3883 & 369.5662 & 369.1105 & 362 \\
\hline 2917000.0 & 370.3006 & 371.5372 & 370.3525 & 370.4865 & 370.608 & 370.6665 & 370.189 & 370.172 & $36 \div$ \\
\hline 2917400.0 & 371.5388 & 372.8288 & 371.996 & 372.0371 & 371.6294 & 371.5274 & 371.4102 & 371.4299 & 370 \\
\hline 2917800.0 & 373.4217 & 374.19 & 373.8131 & 373.4708 & 373.2274 & 373.0174 & 372.7967 & 373.0659 & $37:$ \\
\hline 2918200.0 & 376.0227 & 375.9119 & 375.6657 & 375.3551 & 374.994 & 374.5598 & 374.0711 & 372.8269 & $37 \%$ \\
\hline 2918600.0 & 378.5526 & 378.1814 & 377.6905 & 377.1487 & 376.6605 & 376.1348 & 375.5428 & 373.9316 & $37:$ \\
\hline 2919000.0 & 383.3204 & 380.5551 & 380.1519 & 379.3207 & 378.6115 & 377.9166 & 377.18 & 375.4283 & 37. \\
\hline
\end{tabular}

Figure 16. Mac Operating System X 10.5: Table Viewer in the EverVIEW Slice and Dice Tool that is used to preview a Network Common Data Form (NetCDF) file. 
6. After you have finished previewing the file, click the "Slice and Dice" tab at the top. Now select the grid variable(s) that you want to subset. You can select more than one grid variable by holding the shift or control key while clicking them.

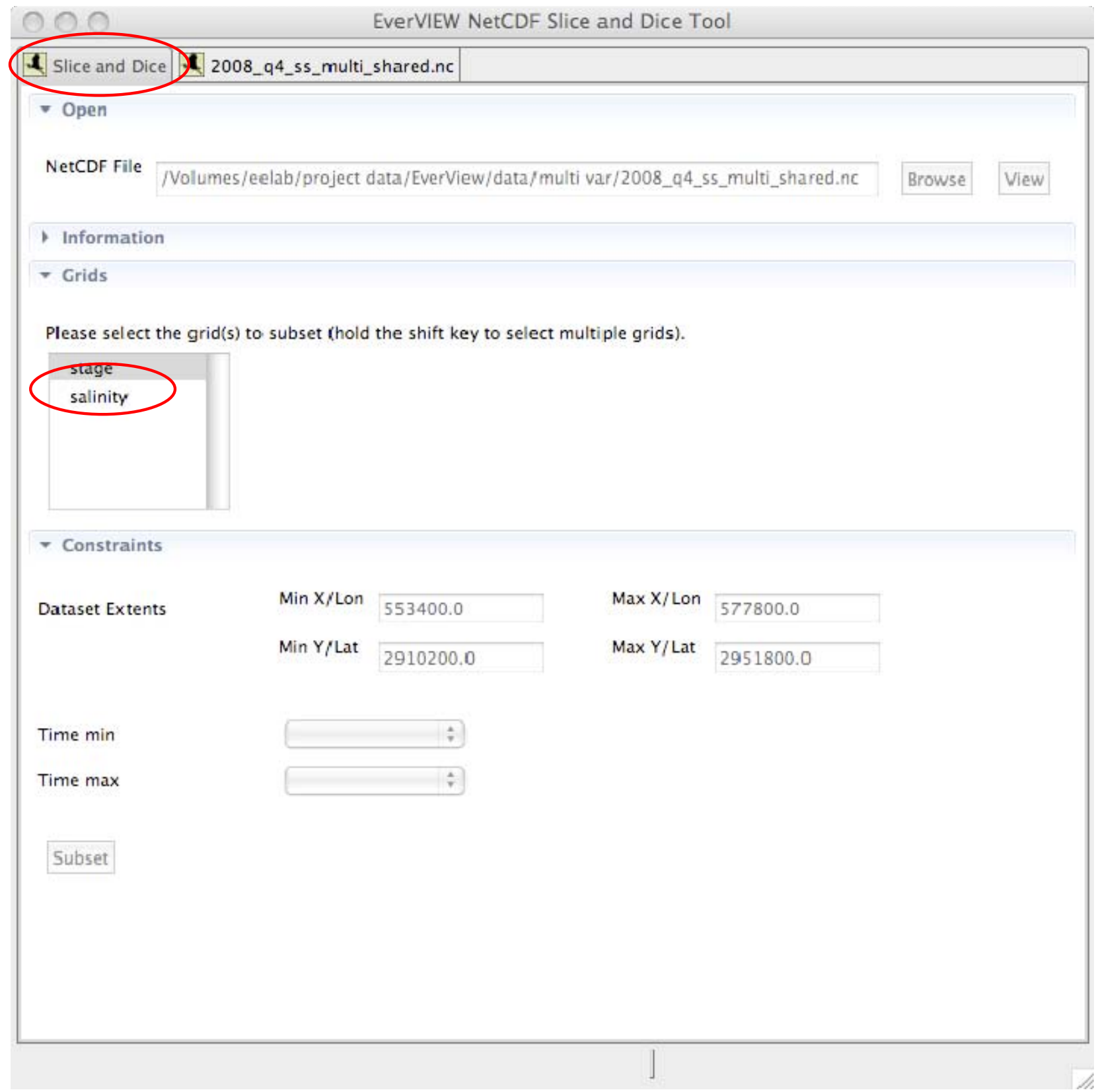

Figure 17. Mac Operating System X 10.5: Selecting grid(s) in the EverVIEW Slice and Dice Tool in order to subset files in Network Commona Data Form (NetCDF). 
7. After selecting the grid(s), the minimum and maximum $x / y$ or latitude/longitude values will be populated in the "Dataset Extents" section.

8. Select the temporal bounds by specifying the start date and the end date from the drop down lists.

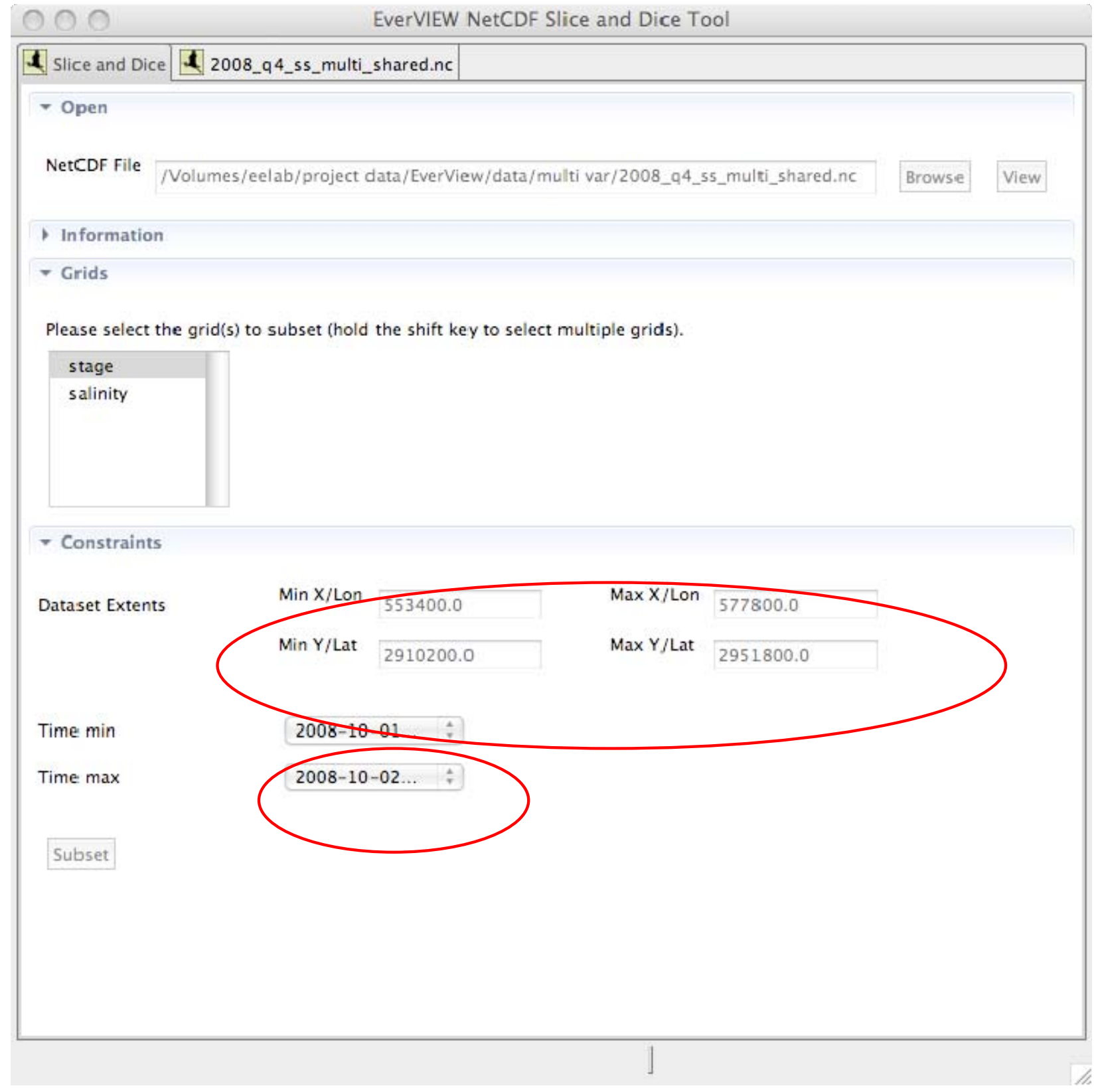

Figure 18. Mac Operating System X 10.5: Defining spatial and temporal bounds in the EverVIEW Slice and Dice Tool in order to subset Network Common Data Form (NetCDF) files. 
9. Click on the "Subset" button to subset the data according to the specified constraints

10. After clicking "Subset," a prompt will appear asking you where to save the subsetted NetCDF file. Type in the name of a new NetCDF file, or select an existing NetCDF file, and click the "Save" button.

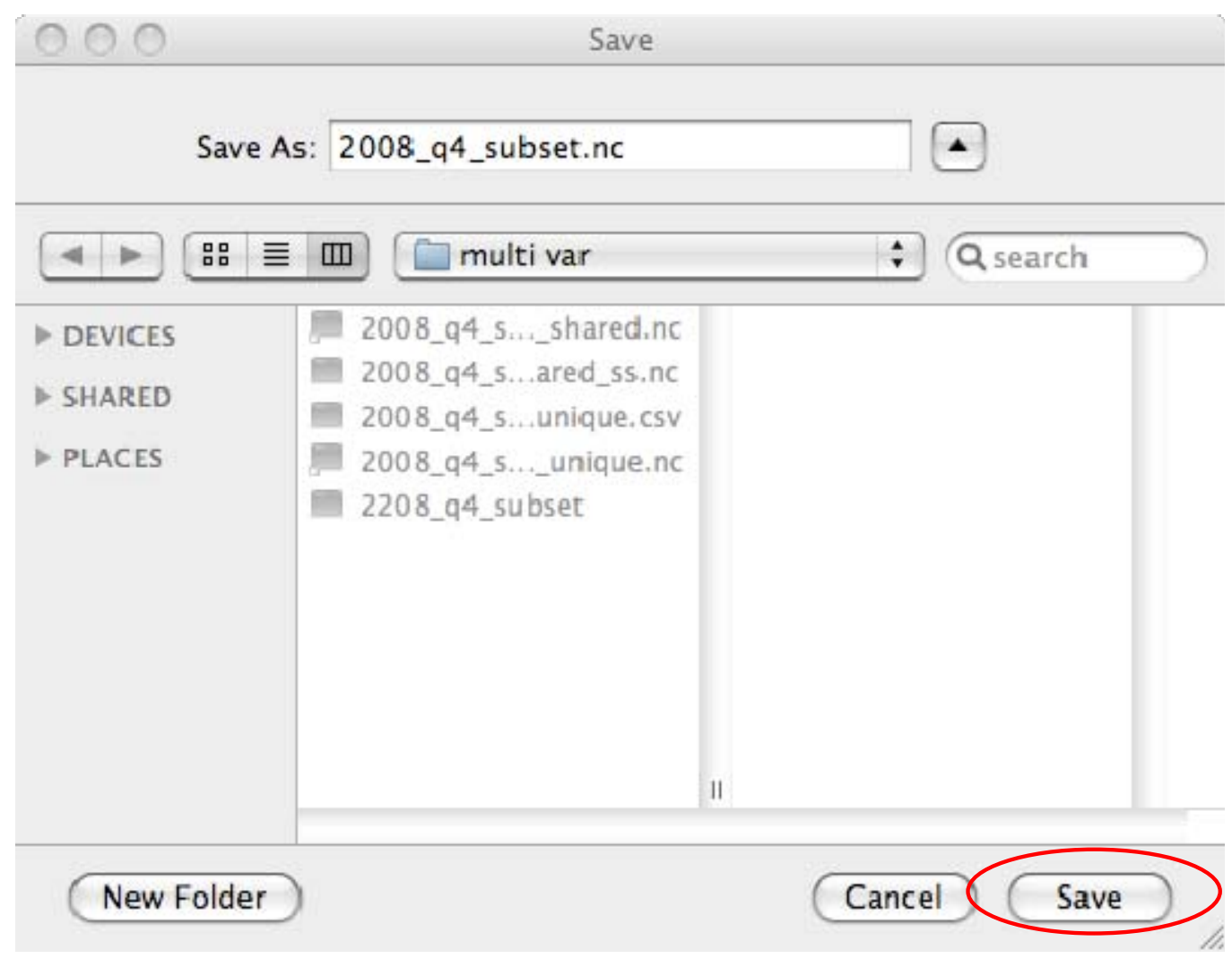

Figure 19. Mac Operating System X 10.5: Saving subsetted Network Common Data Form (NetCDF) files in the EverVIEW NetCDF Slice and Dice Tool. 
11. Once the new NetCDF file has been created, a dialog box will appear letting you know that it was successful.

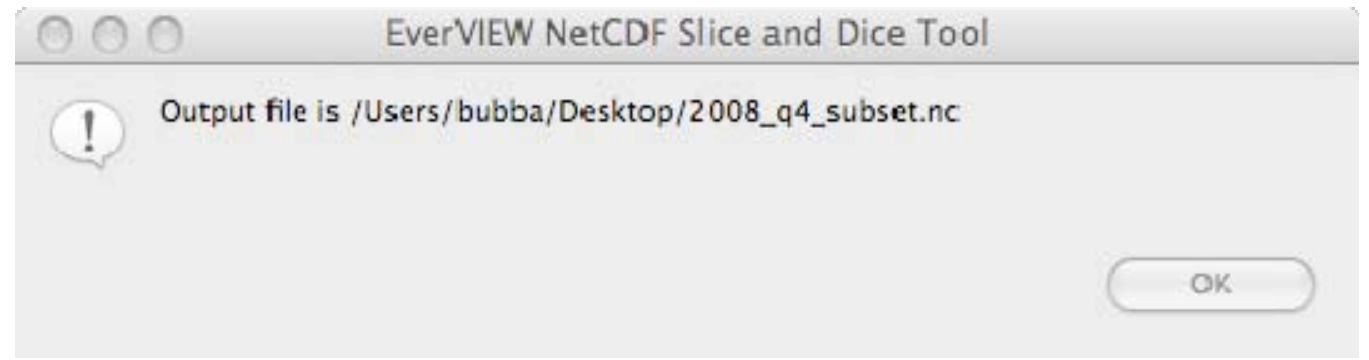

Figure 20. Mac Operating System X 10.5: Success dialog. 
12. The newly created NetCDF file will automatically be opened in the NetCDF Table Viewer.

\section{EverVIEW NetCDF Slice and Dice Tool}

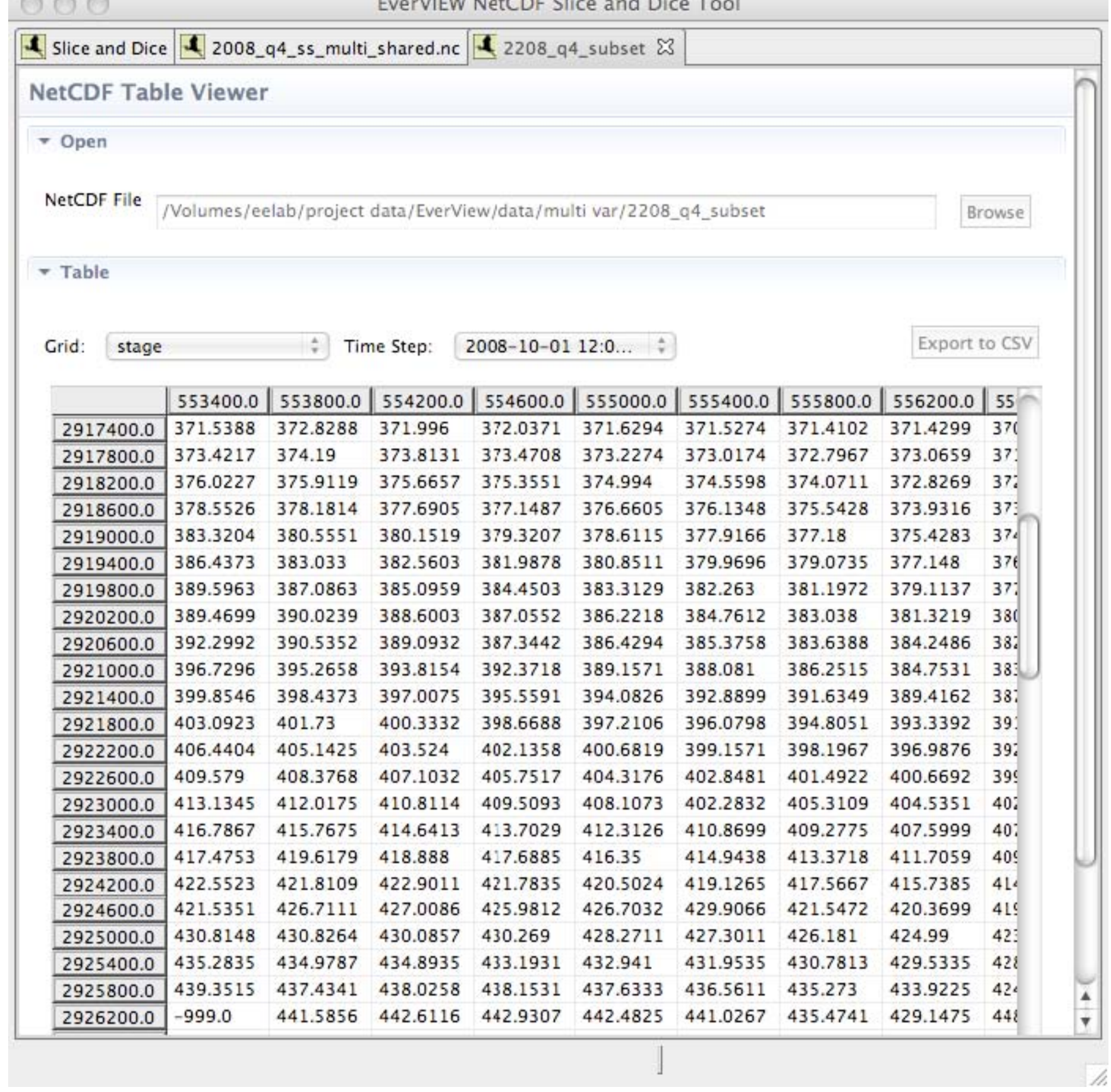

Figure 21. Mac Operating System X 10.5: Table Viewer in the EverVIEW Slice and Dice Tool showing subsetted Network Common Data Form (NetCDF) files. 
13. From here, you can select the grid variable and time step for which you want to view data.

\section{EverVIEW NetCDF Slice and Dice Tool}

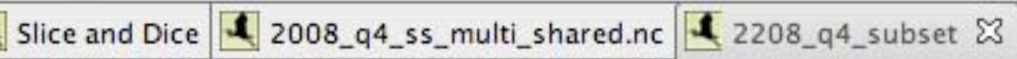

\section{NetCDF Table Viewer}

- Open

NetCDF File

/Volumes/eelab/project data/EverView/data/multi var/2208_q4_subset

Browse

- Table

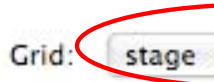

Time Step: 2008-10-01 12:0..

Export to CSV

\begin{tabular}{|c|c|c|c|c|c|c|c|c|c|}
\hline & 553400.0 & 553800.0 & 554200.0 & 554600.0 & 555000.0 & 555400.0 & 555800.0 & 556200.0 & 55 \\
\hline 291 & 1.5388 & 72.8288 & 371.996 & 372.0371 & 371.6294 & 371.5274 & 371.4102 & 371.4299 & \\
\hline 291 & 3.4217 & 74.19 & 373.8131 & 373.4708 & 373.2274 & 373.0174 & 372.7967 & 373.0659 & 37 \\
\hline 00.0 & 76.0227 & 375.9119 & 375.6657 & 375.3551 & 374.994 & 374.5598 & 374.0711 & 372.8269 & $37 \%$ \\
\hline 29. & 78.5526 & 78.1814 & 377.6905 & 377.1487 & 376.6605 & 376.1348 & 428 & 16 & 4 \\
\hline 29 & 33.3204 & 380.5551 & 380.1519 & 379.3207 & 378.6115 & 166 & 377 & 33 & \\
\hline & 36.4373 & 383.033 & r & 3 & 3 & 6 & 3 & & \\
\hline & 3 & 3 & 3 & 3 & 29 & 382.263 & 2 & 7 & \\
\hline 2 & 39.4699 & 39 & 388.6003 & 52 & 386.2 & 384. & 383 & 19 & \\
\hline 2 & 2.2992 & 90.5352 & 389.0932 & 442 & 386.4294 & 385.3 & 383.6388 & 384.2486 & \\
\hline 29 & 6.7296 & 395.2658 & 393.8154 & 392.3718 & 389.1571 & 388.081 & 386.2515 & 531 & \\
\hline 29 & 399.8546 & 398.4373 & 397.0075 & 395.5591 & 394.0826 & 392.8899 & 49 & 2 & 3 \\
\hline 29 & 03.0923 & 401.73 & 400.3332 & 398.6688 & 397.2106 & 396.0798 & 394.8051 & 3.3392 & 39 \\
\hline 29 & s. & 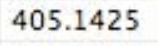 & 4 & 8 & 9 & & & & $39:$ \\
\hline & & & 4 & 17 & 76 & 31 & 40 & 92 & 3 \\
\hline & 413. & & 410.8 & 93 & 408. & 40 & 09 & 351 & 40 \\
\hline 292. & 416.7867 & 415.7675 & 414.6413 & 413.7029 & 412.3126 & 410.8699 & 409.2775 & 407.5999 & 40 \\
\hline 297 & 417.4753 & 419.6179 & 418.888 & 417.6885 & 416.35 & 414.9438 & 413.3718 & 411.7059 & 4 \\
\hline 29 & 422.5523 & 421.8109 & 9011 & 421 & 420.5024 & 65 & 67 & 415 & \\
\hline 29 & 4 & 11 & 4 & 812 & 32 & 56 & 42 & 99 & 41 \\
\hline 00.0 & 430.8148 & 430 & 4 & 4 & 1 & 1 & & & 42 \\
\hline 00.0 & 435.2 & 9787 & 43 & 433.1931 & 2.941 & 431.95 & 813 & 429.5335 & \\
\hline 2925800.0 & 439.351 & 437.4341 & 438.0258 & 438.1531 & 437.6333 & 436.5611 & 435.273 & 433.9225 & \\
\hline 29 & -999.0 & 441.5856 & 442.6116 & 442.9307 & 442.4825 & 441.0267 & 435.4741 & 429.1475 & \\
\hline
\end{tabular}

Figure 22. Mac Operating System X 10.5: Selecting the grid and time step in the Table Viewer of the EverVIEW

Slice and Dice Tool. 
14. From this view, you can also export the data for the current Grid and Time Step to CSV format by clicking the "Export to CSV" button.

EverVIEW NetCDF Slice and Dice Tool

\begin{tabular}{|c|c|c|c|c|c|c|c|c|c|c|}
\hline 1 Slice and Dice & \multicolumn{3}{|c|}{ I 2008_q4_ss_multi_shared.nc } & \multicolumn{6}{|c|}{$\mathbf{A} 2208$ _44_subset $\sum_{3}$} & \\
\hline \multicolumn{10}{|c|}{ NetCDF Table Viewer } & \\
\hline \multicolumn{10}{|l|}{ Open } & \\
\hline NetCDF File & \multicolumn{8}{|c|}{ /Volumes/eelab/project data/EverView/data/multi var/2208_q4_subset } & Browse & \\
\hline \multicolumn{10}{|l|}{ Table } & \\
\hline \multirow[t]{2}{*}{ Grid: } & \multicolumn{3}{|c|}{ Time Step: } & \multicolumn{2}{|c|}{$2008-10-0112: 0 \ldots \quad \vdots$} & \multicolumn{4}{|c|}{ Export to CSV } & \\
\hline & 553400.0 & 553800.0 & 554200.0 & 554600.0 & 555000.0 & 555400.0 & 555800.0 & 556200.0 & 55 & \\
\hline 2917400.0 & 371.5388 & 372.8288 & 371.996 & 372.0371 & 371.6294 & 371.5274 & 371.4102 & 371.4299 & 370 & \\
\hline 2917800.0 & 373.4217 & 374.19 & 373.8131 & 373.4708 & 373.2274 & 373.0174 & 372.7967 & 373.0659 & $37:$ & \\
\hline 2918200.0 & 376.0227 & 375.9119 & 375.6657 & 375.3551 & 374.994 & 374.5598 & 374.0711 & 372.8269 & $37 \%$ & \\
\hline 2918600.0 & 378.5526 & 378.1814 & 377.6905 & 377.1487 & 376.6605 & 376.1348 & 375.5428 & 373.9316 & $37:$ & \\
\hline 2919000.0 & 383.3204 & 380.5551 & 380.1519 & 379.3207 & 378.6115 & 377.9166 & 377.18 & 375.4283 & 374 & \\
\hline 2919400.0 & 386.4373 & 383.033 & 382.5603 & 381.9878 & 380.8511 & 379.9696 & 379.0735 & 377.148 & $37 t$ & \\
\hline 2919800.0 & 389.5963 & 387.0863 & 385.0959 & 384.4503 & 383.3129 & 382.263 & 381.1972 & 379.1137 & $37 \%$ & \\
\hline 2920200.0 & 389.4699 & 390.0239 & 388.6003 & 387.0552 & 386.2218 & 384.7612 & 383.038 & 381.3219 & 380 & \\
\hline 2920600.0 & 392.2992 & 390.5352 & 389.0932 & 387.3442 & 386.4294 & 385.3758 & 383.6388 & 384.2486 & 38: & \\
\hline 2921000.0 & 396.7296 & 395.2658 & 393.8154 & 392.3718 & 389.1571 & 388.081 & 386.2515 & 384.7531 & $38:$ & \\
\hline 2921400.0 & 399.8546 & 398.4373 & 397.0075 & 395.5591 & 394.0826 & 392.8899 & 391.6349 & 389.4162 & $38:$ & \\
\hline 2921800.0 & 403.0923 & 401.73 & 400.3332 & 398.6688 & 397.2106 & 396.0798 & 394.8051 & 393.3392 & $39:$ & \\
\hline 2922200.0 & 406.4404 & 405.1425 & 403.524 & 402.1358 & 400.6819 & 399.1571 & 398.1967 & 396.9876 & $39:$ & \\
\hline 2922600.0 & 409.579 & 408.3768 & 407.1032 & 405.7517 & 404.3176 & 402.8481 & 401.4922 & 400.6692 & $39 !$ & \\
\hline 2923000.0 & 413.1345 & 412.0175 & 410.8114 & 409.5093 & 408.1073 & 402.2832 & 405.3109 & 404.5351 & $40:$ & \\
\hline 2923400.0 & 416.7867 & 415.7675 & 414.6413 & 413.7029 & 412.3126 & 410.8699 & 409.2775 & 407.5999 & $40:$ & \\
\hline 2923800.0 & 417.4753 & 419.6179 & 418.888 & 417.6885 & 416.35 & 414.9438 & 413.3718 & 411.7059 & $40 \varsigma$ & \\
\hline 2924200.0 & 422.5523 & 421.8109 & 422.9011 & 421.7835 & 420.5024 & 419.1265 & 417.5667 & 415.7385 & $4 \mathrm{~L}$ & \\
\hline 2924600.0 & 421.5351 & 426.7111 & 427.0086 & 425.9812 & 426.7032 & 429.9066 & 421.5472 & 420.3699 & $4 L S$ & \\
\hline 2925000.0 & 430.8148 & 430.8264 & 430.0857 & 430.269 & 428.2711 & 427.3011 & 426.181 & 424.99 & $42:$ & \\
\hline 2925400.0 & 435.2835 & 434.9787 & 434.8935 & 433.1931 & 432.941 & 431.9535 & 430.7813 & 429.5335 & 422 & \\
\hline 2925800.0 & 439.3515 & 437.4341 & 438.0258 & 438.1531 & 437.6333 & 436.5611 & 435.273 & 433.9225 & 42 & \\
\hline 2926200.0 & -999.0 & 441.5856 & 442.6116 & 442.9307 & 442.4825 & 441.0267 & 435.4741 & 429.1475 & 442 & - \\
\hline
\end{tabular}

Figure 23. Mac Operating System X 10.5: Exporting a grid to a comma-separated value (CSV) file in the EverVIEW NetCDF Slice and Dice Tool. 


\section{Ubuntu 8.10}

Installation

The software is available for download at http://jem.cr.usgs.gov/everview.aspx. Extract the zip file into a folder on your local machine and run the executable file. This software requires write permission to the installation directory in order to function properly. 


\section{User Instructions}

1. Run the application. To do this, navigate to the folder where the tool is installed and double click on EverVIEW_NetCDFSDTool. You may need to give the file permissions to execute as a program in order for it to run. The application can only be run from this directory, because it depends on other files and folders in the installation directory.

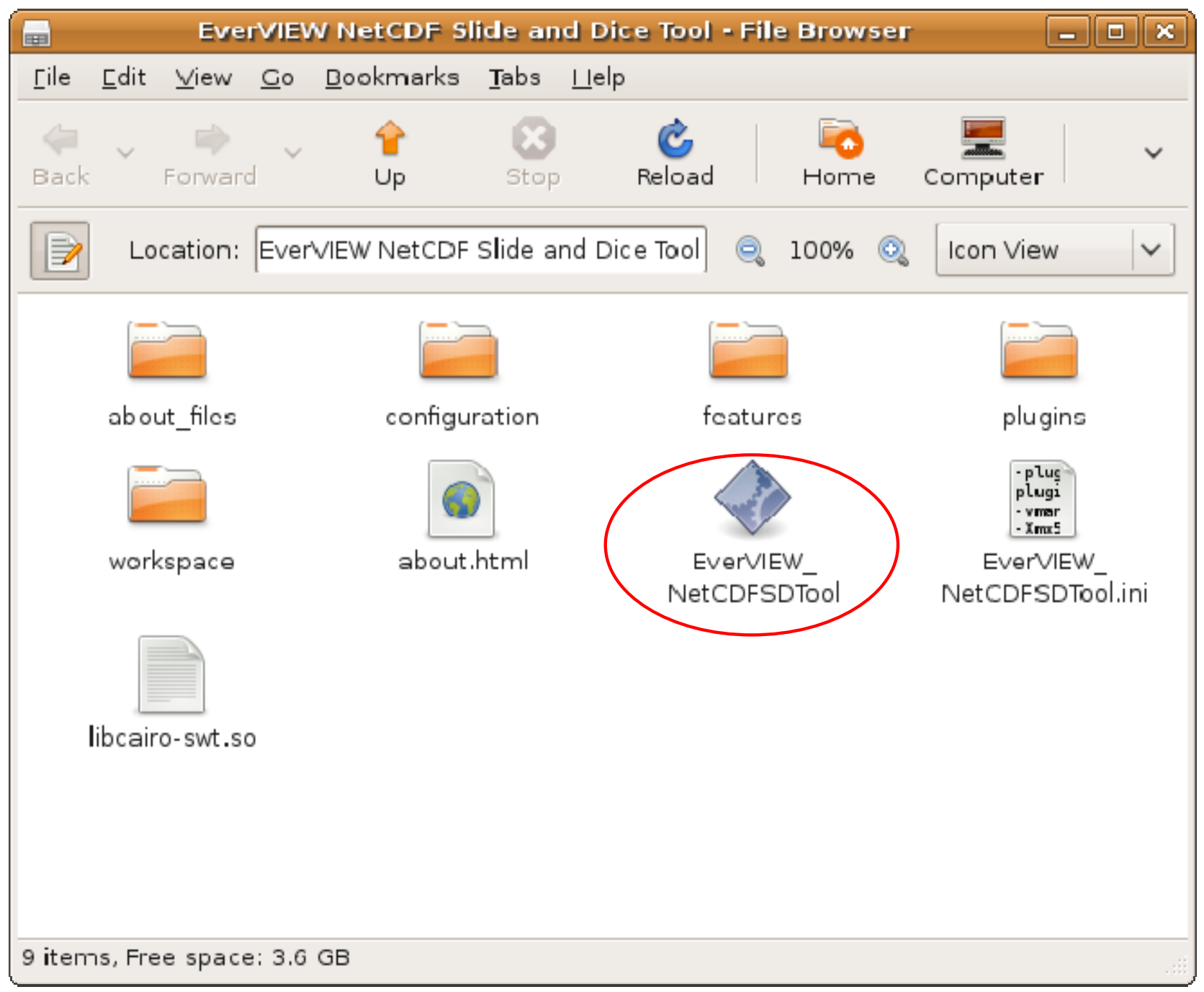

Figure 24. Ubuntu 8.10: Installation folder showing the EverVIEW_NetCDFSDTool executable. 
2. The EverVIEW NetCDF Slice and Dice Tool will open and check to see if any updates are available.

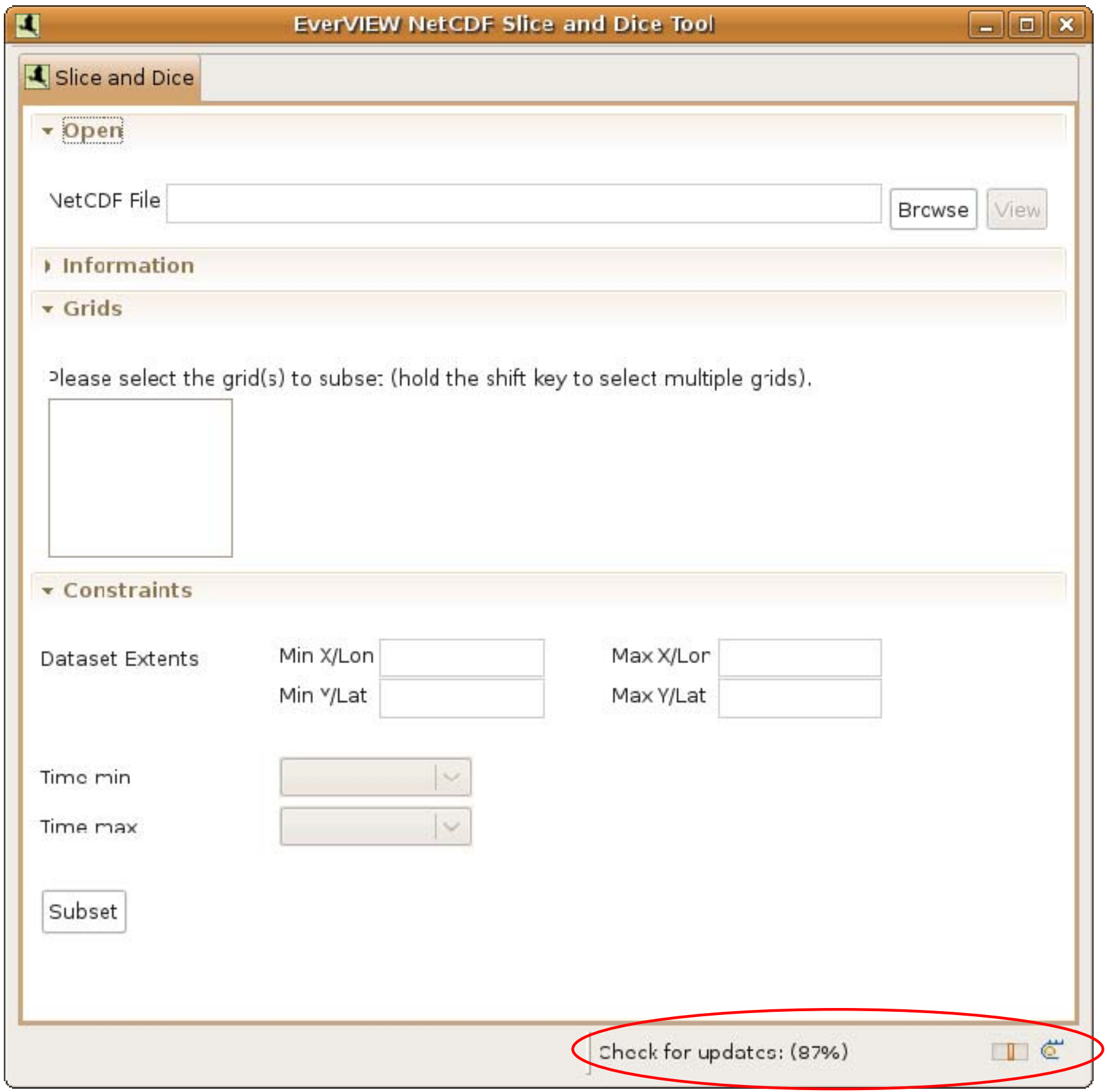

Figure 25. Ubuntu 8.10: Automatic updates. 
3. Click the "Browse" button and select the NetCDF file to subset.

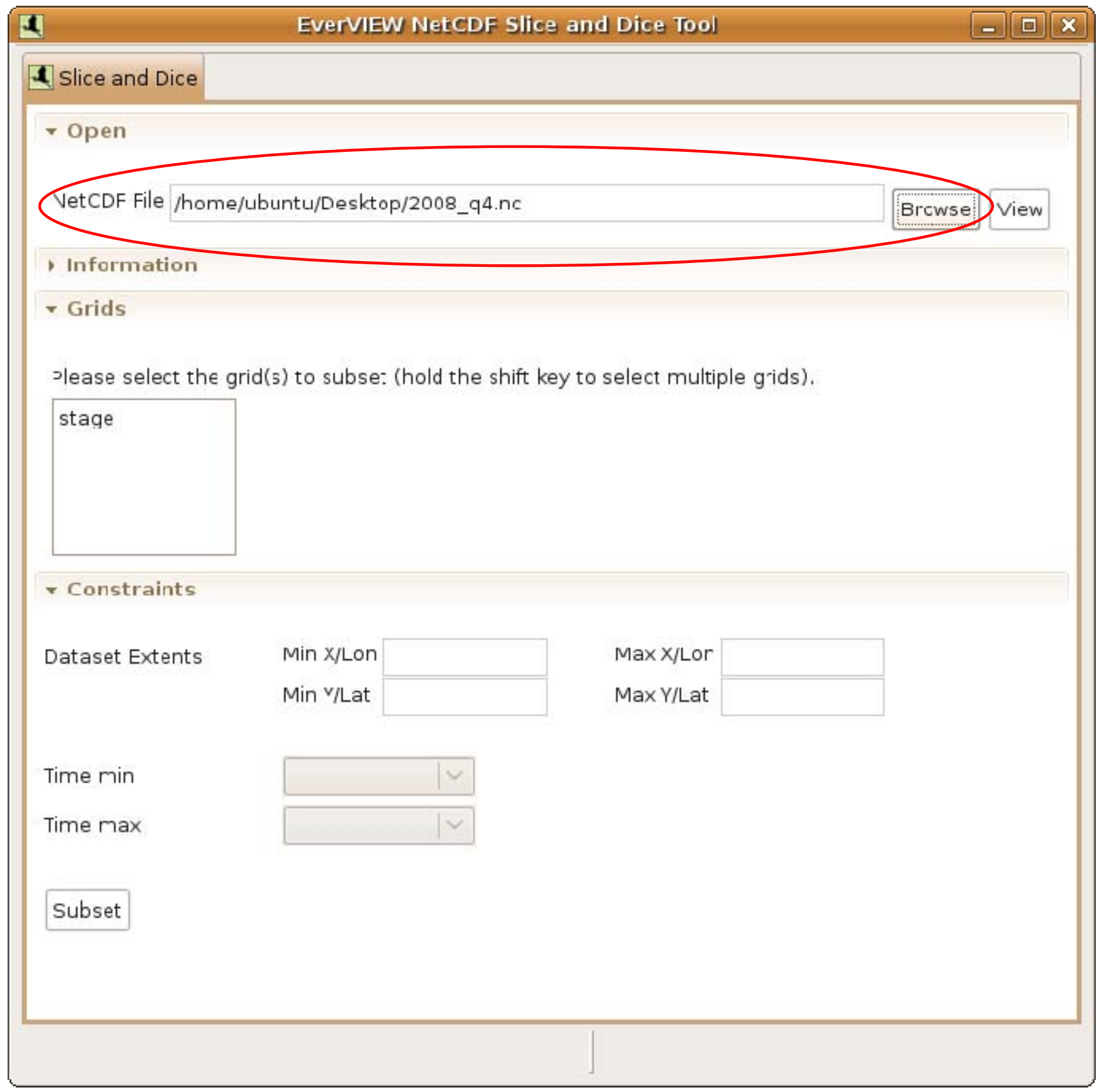

Figure 26. Ubuntu 8.10: Opening a Network Common Data Form (NetCDF) file in EverVIEW. 
4. If you would like to preview the original NetCDF file, click the "View" button.

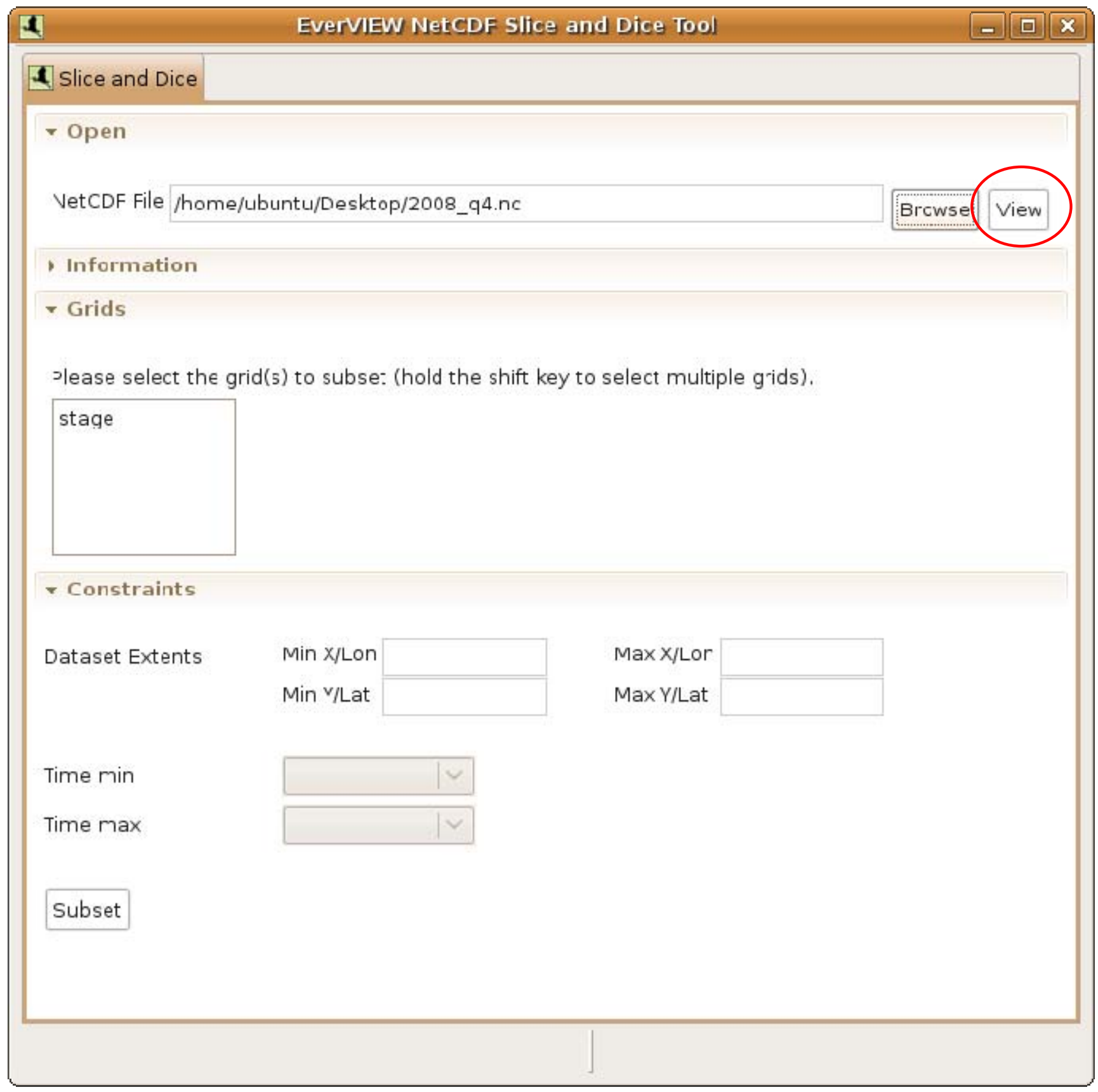

Figure 27. Ubuntu 8.10: Previewing a Network Common Data Form (NetCDF) file in the EverVIEW NetCDF Slice and Dice Tool. 
5. After clicking the "View" button, the NetCDF Table Viewer will be shown with the NetCDF file you selected.

\begin{tabular}{|c|c|c|c|c|c|c|c|c|c|}
\hline & \multicolumn{7}{|c|}{ EvervIEW NetcDF sllce and Dice Tool } & 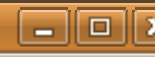 \\
\hline \multicolumn{10}{|c|}{4 slice and Dice $\$ 2008$ _q4.rc \& } \\
\hline \multicolumn{10}{|c|}{ NetCDF Table Viewer } \\
\hline \multicolumn{10}{|l|}{ - Open } \\
\hline \multicolumn{8}{|c|}{ NetCDF File /hom $1 /$ ubıntu/Desktop/2008_q4.nc } & \multicolumn{2}{|c|}{ Browse } \\
\hline \multicolumn{10}{|l|}{ - Table } \\
\hline \multirow[t]{2}{*}{ Grid: stage } & \multicolumn{3}{|c|}{ Time Step: } & \multicolumn{3}{|c|}{ 2003-10-01 12:00: $\checkmark$} & & \multicolumn{2}{|c|}{ Export to CSV } \\
\hline & $463 . .0$ & $463 \ldots .0$ & $464 \ldots 0$ & $464 \ldots 0$ & $465 \ldots 0$ & $465 \ldots .0$ & $465 \ldots 0$ & $466 \ldots 0$ & $\hat{\theta}$ \\
\hline $2790200 . \mathrm{C}$ & $\mathrm{NaN}$ & $\mathrm{NaN}$ & $\mathrm{NaN}$ & NaN & $\mathrm{Na \Lambda}$ & $\mathrm{NaN}$ & $\mathrm{NaN}$ & $\mathrm{NaN}$ & $\equiv$ \\
\hline $2790600 . C$ & $\mathrm{NaN}$ & $\mathrm{NaN}$ & $\mathrm{NaN}$ & NaN & Na凡 & $\mathrm{NaN}$ & $\mathrm{NaN}$ & $\mathrm{NaN}$ & \\
\hline $2791000 . \mathrm{C}$ & $\mathrm{NaN}$ & $\mathrm{NaN}$ & $\mathrm{NaN}$ & NaN & NaN & $\mathrm{NaN}$ & $\mathrm{NaN}$ & $\mathrm{NaN}$ & \\
\hline $2791400 . C$ & $\mathrm{NaN}$ & $\mathrm{NaN}$ & $\mathrm{NaN}$ & $\mathrm{NaN}$ & Na凡 & $\mathrm{NaN}$ & $\mathrm{NaN}$ & $\mathrm{NaN}$ & \\
\hline $2791800 . C$ & $\mathrm{NaN}$ & $\mathrm{NaN}$ & $\mathrm{NaN}$ & NaN & Na凡 & $\mathrm{\Lambda aN}$ & $\mathrm{NaN}$ & $\mathrm{NaN}$ & \\
\hline $2792200 . C$ & $\mathrm{NaN}$ & $\mathrm{NaN}$ & $\mathrm{NaN}$ & NaN & Na凡 & $\mathrm{\Lambda aN}$ & $\mathrm{NaN}$ & $\mathrm{NaN}$ & \\
\hline $2792600 . C$ & $\mathrm{NaN}$ & $\mathrm{NaN}$ & $\mathrm{NaN}$ & NaN & Na凡 & $\mathrm{NaN}$ & $\mathrm{NaN}$ & $\mathrm{NaN}$ & \\
\hline $2 / 93000.0$ & NaN & NaN & NaN & Narv & INaN & NaN & NaN & $\mathrm{NaN}$ & \\
\hline $2793400 . \mathrm{C}$ & NaN & $\mathrm{NaN}$ & $\mathrm{NaN}$ & $\mathrm{NaN}$ & Nan & $\mathrm{NaN}$ & $\mathrm{NaN}$ & $N \bar{e} N$ & \\
\hline $2793800 . \mathrm{C}$ & NaN & NaN & NaN & NaN & Nan & $\mathrm{NaN}$ & $\mathrm{NaN}$ & $\mathrm{N} \subset \mathrm{N}$ & \\
\hline $2794200 . C$ & $\mathrm{NaN}$ & $\mathrm{NaN}$ & NaN & NaN & NaN & NaN & $\mathrm{NaN}$ & $\mathrm{Nan}$ & \\
\hline $2794600 . C$ & $\mathrm{NaN}$ & $\mathrm{NaN}$ & $\mathrm{NaN}$ & NaN & $\mathrm{Na \Lambda}$ & $\mathrm{NaN}$ & $\mathrm{NaN}$ & $\mathrm{NaN}$ & \\
\hline $2795000 . C$ & $\mathrm{NaN}$ & $\mathrm{NaN}$ & $\mathrm{NaN}$ & $\mathrm{NaN}$ & Na凡 & $\mathrm{NaN}$ & $\mathrm{NaN}$ & $\mathrm{N} a \mathrm{~N}$ & \\
\hline $2795400 . C$ & $\mathrm{NaN}$ & $\mathrm{NaN}$ & $\mathrm{NaN}$ & NaN & NaA & $\mathrm{NaN}$ & $\mathrm{NaN}$ & $\mathrm{NaN}$ & \\
\hline $2795800 . C$ & $\mathrm{NaN}$ & $\mathrm{NaN}$ & $\mathrm{NaN}$ & $\mathrm{NaN}$ & Na凡 & $\mathrm{\Lambda aN}$ & $\mathrm{NaN}$ & $\mathrm{NaN}$ & \\
\hline $2796200 . C$ & $\mathrm{NaN}$ & $\mathrm{NaN}$ & $\mathrm{NaN}$ & NaN & Na凡 & $\mathrm{NaN}$ & $\mathrm{NaN}$ & $\mathrm{NaN}$ & \\
\hline $2796600 . \mathrm{C}$ & $\mathrm{NaN}$ & $\mathrm{NaN}$ & $\mathrm{NaN}$ & NaN & NaN & $\mathrm{NaN}$ & $\mathrm{NaN}$ & $\mathrm{N} a \mathrm{~N}$ & \\
\hline $2797000 . C$ & NaN & $\mathrm{NaN}$ & NaN & NaN & INan & NaN & NaN & $\mathrm{NaN}$ & \\
\hline $2797400 . \mathrm{C}$ & $\mathrm{NaN}$ & $\mathrm{NaN}$ & $\mathrm{NaN}$ & NaN & Nan & NaN & $\mathrm{NaN}$ & $\mathrm{NeN}$ & \\
\hline $2797800 . \mathrm{C}$ & $\mathrm{NaN}$ & $\mathrm{NaN}$ & $\mathrm{NaN}$ & NaN & Nan & $\mathrm{naN}$ & $\mathrm{NaN}$ & $\mathrm{NeN}$ & \\
\hline $2798200 . \mathrm{C}$ & $\mathrm{NaN}$ & $\mathrm{NaN}$ & NaN & NaN & Na\} $&{\mathrm{NaN}} &{\mathrm{NaN}} &{\mathrm{NaN}} &{ } \\
{\hline 2798600 . C} &{\mathrm{NaN}} &{\mathrm{NaN}} &{\text { NaN }} &{\text { NaN }} &{\text { Na凡 }} &{\text { NaN }} &{\mathrm{NaN}} &{\mathrm{NaN}} &{\checkmark} \\
{\hline \begin{array}{|l|l|l|}< & \text { III } \\
\end{array}} &{ } &{ } &{ } &{ } &{ } &{ } &{ } &{ } &{ } \\
$\hline
\end{tabular}

Figure 28. Ubuntu 8.10: Table Viewer in the EverVIEW Slice and Dice Tool used to preview a Network Common Data Form (NetCDF) file. 
6. After you have finished previewing the file, click the "Slice and Dice" tab at the top. Now select the grid variable(s) that you want to subset. You can select more than one grid variable by holding the shift or control key while clicking them.

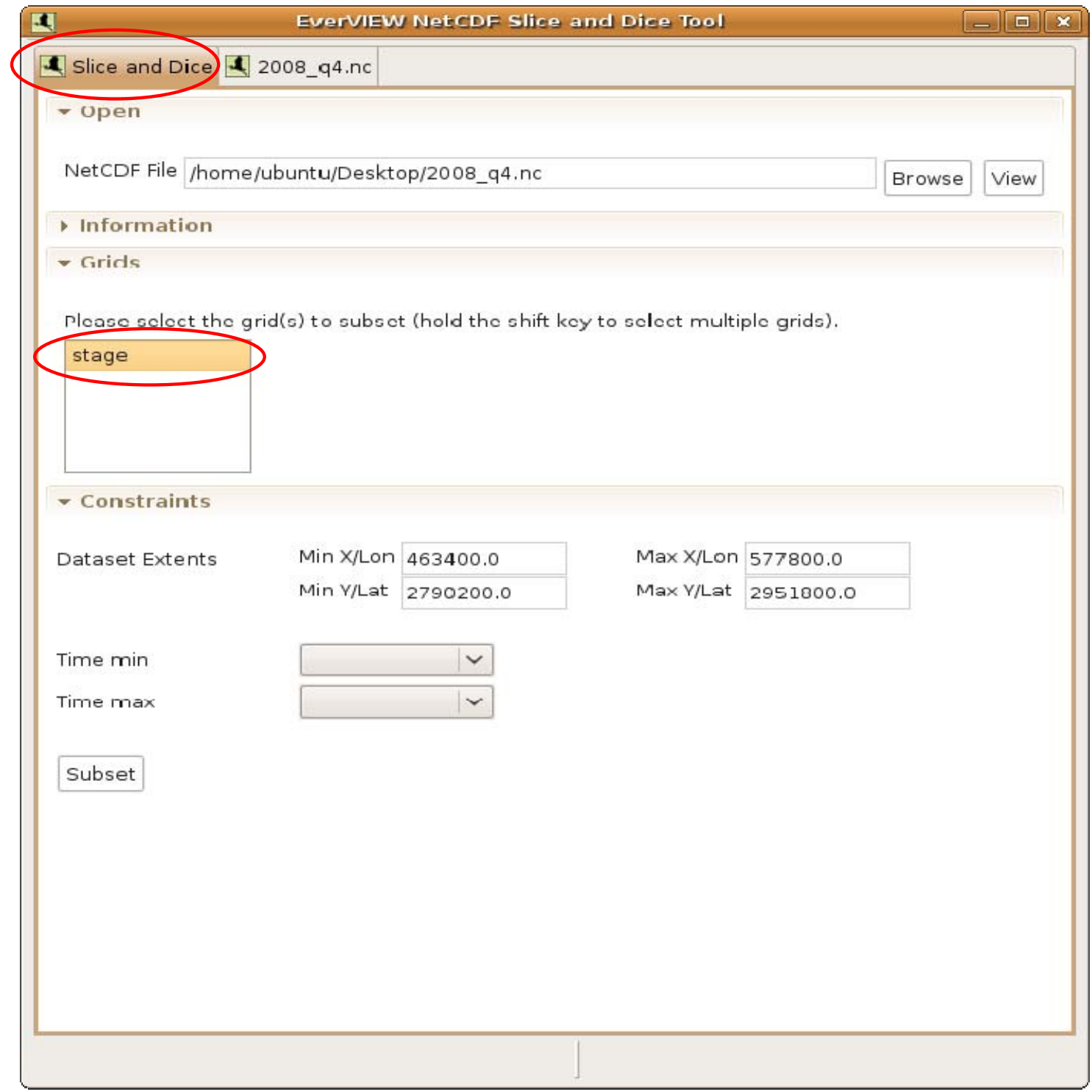

Figure 29. Ubuntu 8.10: Selecting grid(s) in the EverVIEW Slice and Dice Tool in order to subset Network Commona Data Form (NetCDF) files. 
7. After selecting the grid(s), the minimum and maximum $x / y$ or latitude/longitude values will be populated in the "Dataset Extents" section.

8. Select the temporal bounds by specifying the start date and the end date from the drop-down lists.

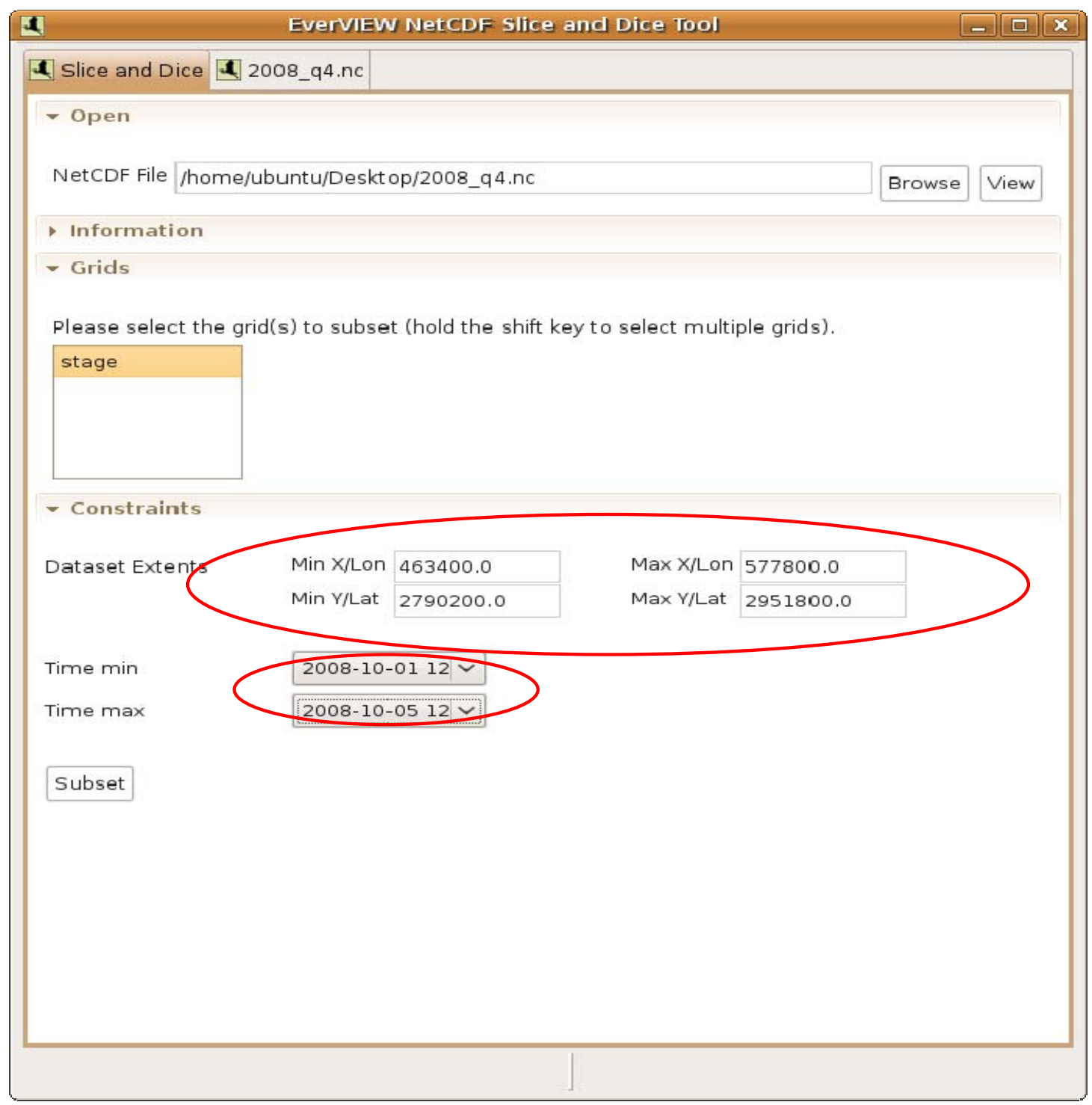

Figure 30. Ubuntu 8.10: Defining spatial and temporal bounds in the EverVIEW Slice and Dice Tool in order to subset Network Common Data Form (NetCDF) files. 
9. Click on the "Subset" button to subset the data according to the specified constraints

10. After clicking "Subset," a prompt will appear asking you where to save the subsetted NetCDF file. Type in the name of a new NetCDF file, or select an existing NetCDF file, and click the "Save" button.

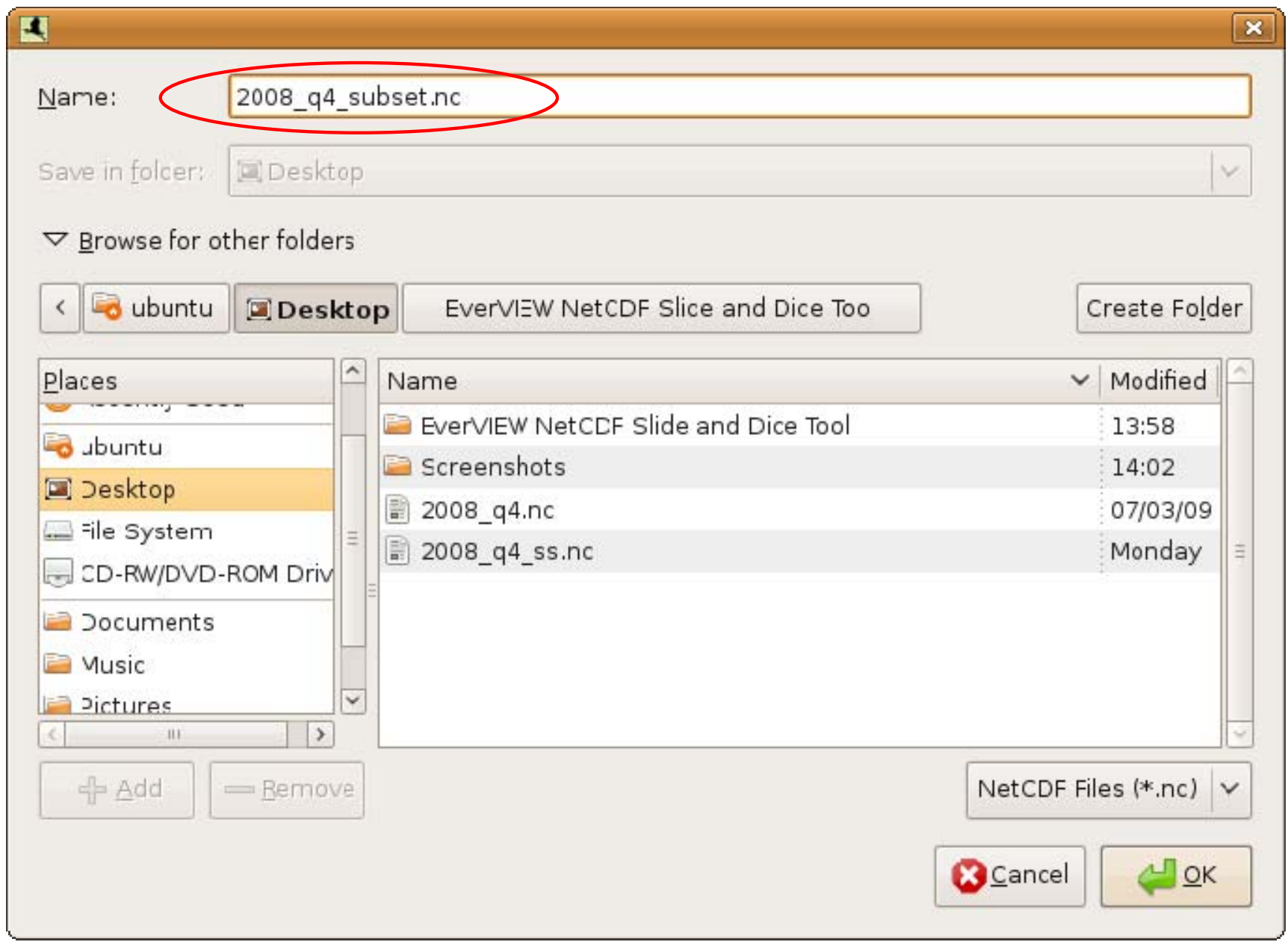

Figure 31. Ubuntu 8.10: Saving subsetted Network Common Data Form (NetCDF) files in the EverVIEW NetCDF Slice and Dice Tool. 
11. Once the new NetCDF file has been created, a dialog box will appear letting you know that it was successful.

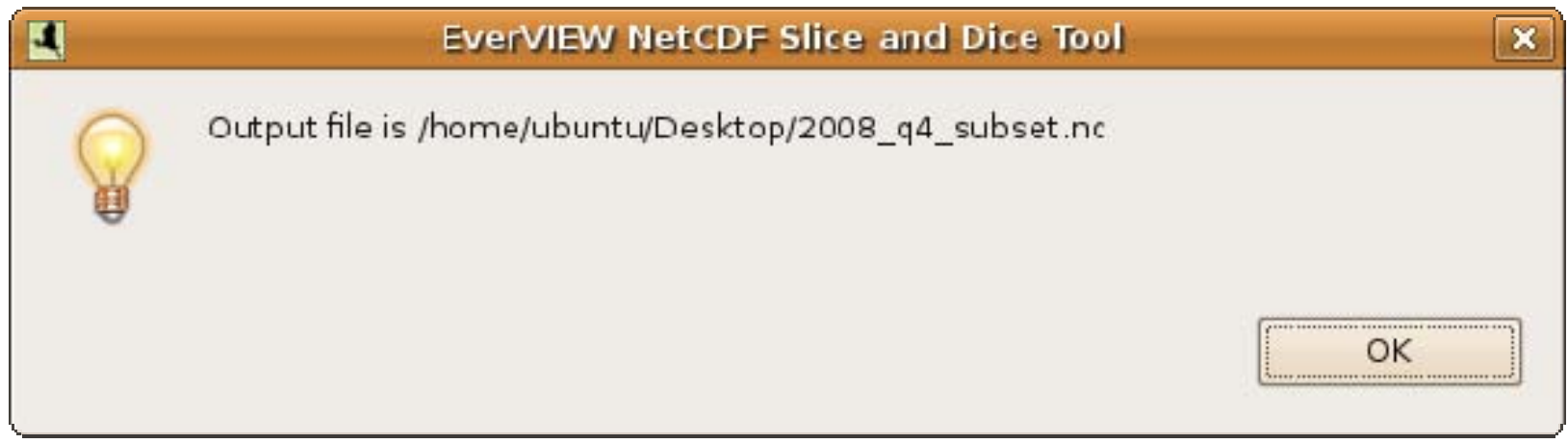

Figure 32. Ubuntu 8.10: Success dialog. 
12. The newly created NetCDF file will automatically be opened in the NetCDF Table Viewer.

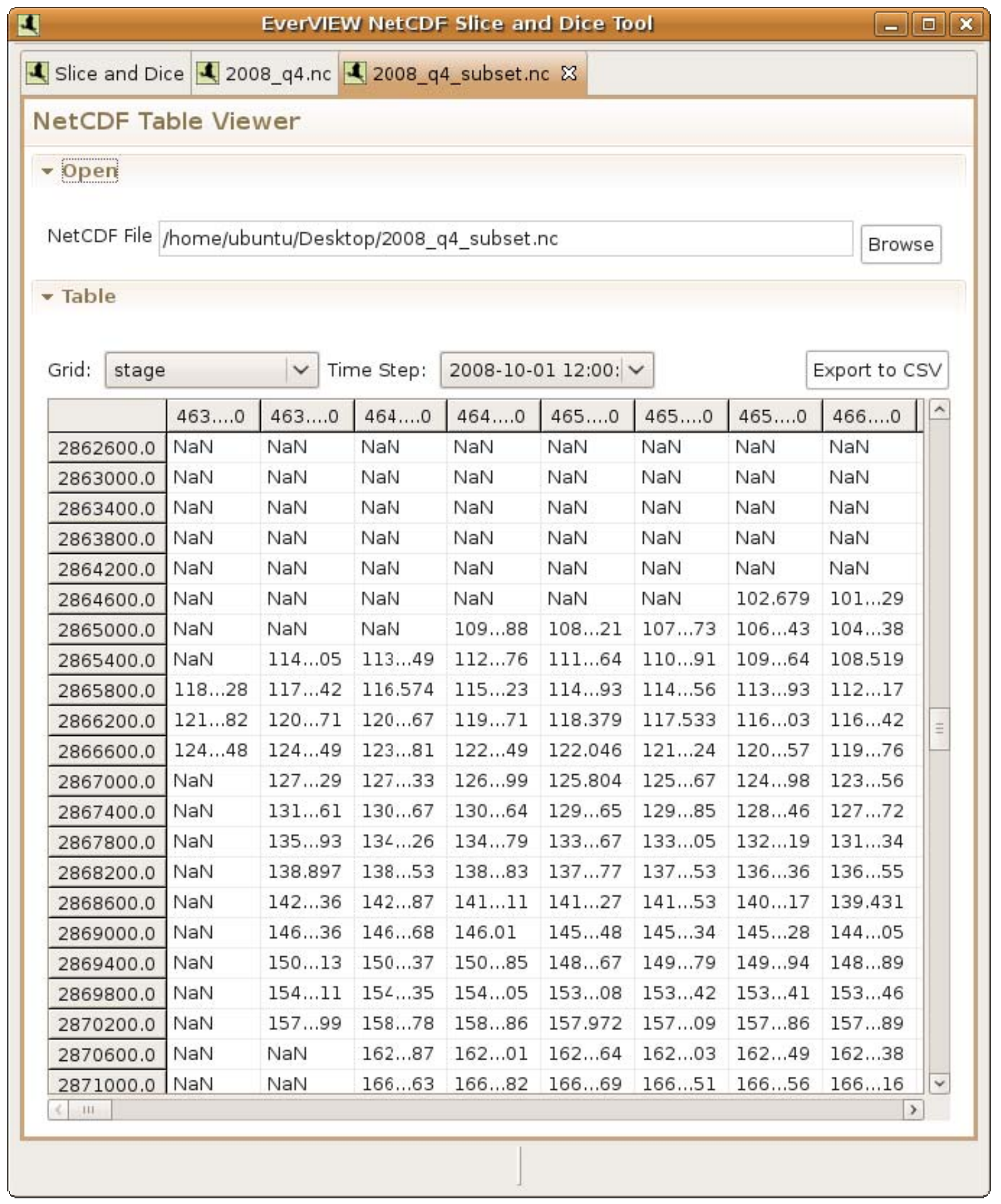

Figure 33. Ubuntu 8.10: Table Viewer in the EverVIEW Slice and Dice Tool showing subsetted Network Common Data Form (NetCDF) files. 
13. From here you can select the grid variable and time step for which you want to view data.

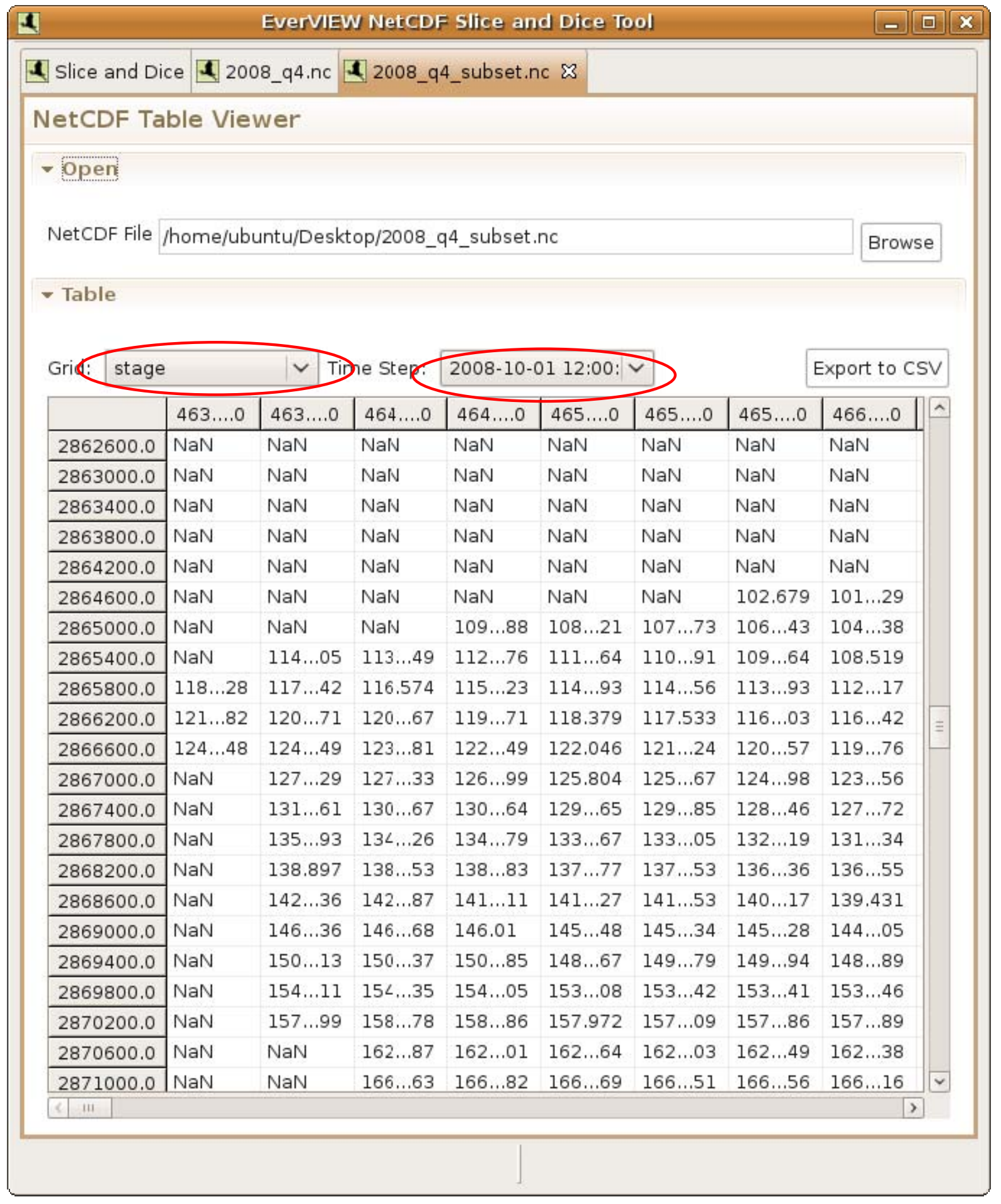

Figure 34. Ubuntu 8.10: Selecting the grid and time step in the Table Viewer of the EverVIEW Slice and Dice Tool. 
14. From this view, you can also export the data for the current Grid and Time Step to CSV format by clicking the "Export to CSV" button.

\begin{tabular}{|c|c|c|c|c|c|c|c|c|c|c|}
\hline \multicolumn{2}{|l|}{ 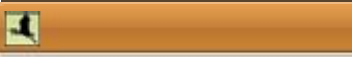 } & \multicolumn{6}{|c|}{ EverVIEW NetCDF Slitce and Dice Tool } & \multirow{2}{*}{\multicolumn{3}{|c|}{ 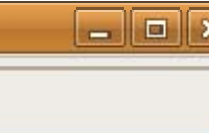 }} \\
\hline \multicolumn{8}{|c|}{ slice and Dice } & & & \\
\hline \multicolumn{11}{|c|}{ NetCDF Table Viewer } \\
\hline \multicolumn{11}{|l|}{ - Open } \\
\hline NetCDF File & \multicolumn{7}{|c|}{ /home/ubuntu/Desktop/2008_q4_subset.nc } & \multicolumn{3}{|c|}{ Brawse } \\
\hline \multicolumn{11}{|l|}{ - Table } \\
\hline \multirow[t]{2}{*}{ Grid: stage } & \multicolumn{3}{|c|}{ Time Step: } & \multicolumn{4}{|c|}{ 2008-10-01 12:00: $\checkmark$} & \multicolumn{2}{|c|}{ Export to CSV } & \\
\hline & $463 \ldots 0$ & $463 \ldots 0$ & $464 \ldots 0$ & $464 \ldots . .0$ & $465 \ldots 0$ & $465 \ldots 0$ & $465 \ldots . .0$ & $466 \ldots 0$ & A & r \\
\hline 2862600.0 & $\mathrm{NaN}$ & $\mathrm{NaN}$ & $\mathrm{NaN}$ & $\mathrm{NaN}$ & $\mathrm{NaN}$ & $\mathrm{NaN}$ & $\mathrm{NaN}$ & $\mathrm{NaN}$ & & \\
\hline 2863000.0 & $\mathrm{NaN}$ & $\mathrm{NaN}$ & $\mathrm{NaN}$ & $\mathrm{NaN}$ & $\mathrm{NaN}$ & $\mathrm{NaN}$ & $\mathrm{NaN}$ & $\mathrm{NaN}$ & & \\
\hline 2863400.0 & $\mathrm{NaN}$ & $\mathrm{NaN}$ & $\mathrm{NaN}$ & $\mathrm{NaN}$ & $\mathrm{NaN}$ & $\mathrm{NaN}$ & $\mathrm{NaN}$ & $\mathrm{NaN}$ & & \\
\hline 2863800.0 & $\mathrm{NaN}$ & NaN & NaN & NaN & NaN & NaN & $\mathrm{NaN}$ & NaN & & \\
\hline 2864200.0 & $\mathrm{NaN}$ & $\mathrm{NaN}$ & $\mathrm{NaN}$ & $\mathrm{NaN}$ & $\mathrm{NaN}$ & NaN & $\mathrm{NaN}$ & $\mathrm{NaN}$ & & \\
\hline 2864600.0 & $\mathrm{NaN}$ & $\mathrm{NaN}$ & $\mathrm{NaN}$ & $\mathrm{NaN}$ & $\mathrm{NaN}$ & $\mathrm{NaN}$ & 102.679 & $101 \ldots 29$ & & \\
\hline 2865000.0 & $\mathrm{NaN}$ & $\mathrm{NaN}$ & $\mathrm{NaN}$ & $109 \ldots 88$ & $108 \ldots 21$ & $107 \ldots 73$ & $106 \ldots 43$ & $104 \ldots 38$ & & \\
\hline 2865400.0 & $\mathrm{NaN}$ & $114 \ldots 05$ & $113 \ldots 49$ & $112 \ldots 76$ & $111 \ldots 64$ & $110 \ldots 91$ & $109 \ldots 64$ & 108.519 & & \\
\hline 2865800.0 & $118 \ldots 28$ & $117 \ldots 42$ & 116.574 & $115 \ldots 23$ & $114 \ldots 93$ & $114 \ldots .56$ & $113 \ldots 93$ & $112 \ldots 17$ & & \\
\hline 2866200.0 & $121 \ldots 82$ & $120 \ldots 71$ & $120 \ldots 67$ & $119 \ldots 71$ & 118.379 & 117.533 & $116 \ldots 03$ & $116 \ldots 42$ & $\equiv$ & E \\
\hline 2866600.0 & $124 \ldots 48$ & $124 \ldots 49$ & $123 \ldots 81$ & $122 \ldots 49$ & 122.046 & $121 \ldots 24$ & $120 \ldots 57$ & $119 \ldots 76$ & & \\
\hline 2867000.0 & $\mathrm{NaN}$ & $127 \ldots 29$ & $127 \ldots 33$ & $126 \ldots 99$ & 125.804 & $125 \ldots 67$ & $124 \ldots 98$ & $123 \ldots 56$ & & \\
\hline 2867400,0 & $\mathrm{NaN}$ & $131 \ldots 61$ & $130 \ldots 67$ & $130 \ldots 64$ & $129 \ldots 65$ & $129 \ldots 85$ & $128 \ldots 46$ & $127 \ldots 72$ & & \\
\hline 2867800.0 & $\mathrm{NaN}$ & $135 \ldots 93$ & $134 \ldots 26$ & $134 \ldots 79$ & $133 \ldots 67$ & $133 \ldots 05$ & $132 \ldots 19$ & $131 \ldots 34$ & & \\
\hline 2868200.0 & $\mathrm{NaN}$ & 138.897 & $138 \ldots 53$ & $138 \ldots 83$ & $137 \ldots 77$ & $137 \ldots 53$ & $136 \ldots 36$ & $136 \ldots 55$ & & \\
\hline 2868600.0 & $\mathrm{NaN}$ & $142 \ldots 36$ & $142 \ldots 87$ & $141 \ldots 11$ & $141 \ldots 27$ & $141 \ldots 53$ & $140 \ldots 17$ & 139.431 & & \\
\hline 2869000.0 & $\mathrm{NaN}$ & $146 \ldots 36$ & $146 \ldots 68$ & 146.01 & $145 \ldots 48$ & $145 \ldots 34$ & $145 \ldots 28$ & $144 \ldots 05$ & & \\
\hline 2869400.0 & $\mathrm{NaN}$ & $150 \ldots 13$ & $150 \ldots .37$ & $150 \ldots 85$ & $148 \ldots 67$ & $149 \ldots 79$ & $149 . .94$ & $148 \ldots 89$ & & \\
\hline 2869800.0 & $\mathrm{NaN}$ & $154 \ldots 11$ & $154 \ldots 35$ & $154 \ldots 05$ & $153 \ldots 08$ & $153 \ldots 42$ & $153 \ldots 41$ & $153 \ldots 46$ & & \\
\hline 2870200.0 & $\mathrm{NaN}$ & $157 \ldots 99$ & $158 \ldots 78$ & $158 \ldots 86$ & 157.972 & $157 \ldots .09$ & $157 \ldots 86$ & $157 \ldots 89$ & & \\
\hline 2870600.0 & $\mathrm{NaN}$ & $\mathrm{NaN}$ & $162 \ldots 87$ & $162 \ldots 01$ & $162 \ldots 64$ & $162 \ldots 03$ & $162 \ldots 49$ & $162 \ldots 38$ & & \\
\hline 2871000.0 & $\mathrm{NaN}$ & $\mathrm{NaN}$ & $166 \ldots 63$ & $166 \ldots 82$ & $166 \ldots 69$ & $166 \ldots 51$ & $166 \ldots 56$ & $166 \ldots 16$ & $\checkmark$ & 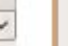 \\
\hline \begin{tabular}{|l|l|} 
& III \\
\end{tabular} & & & & & & & & T & & \\
\hline
\end{tabular}

Figure 35. Ubuntu 8.10: Exporting a grid to a comma-separated value (CSV) file in the EverVIEW NetCDF Slice and Dice Tool. 


\section{References Cited}

Unidata Program Center, 2009, NetCDF User’s Guide.Boulder, Colo., University Coporation for Atmospheric Research, accessed online April 1, 2009, at http://www.unidata.ucar.edu/software/netcdf/docs/netcdf/. 